\title{
Density Changes in the Optimized CSSX Solvent System
}

November 2002

\author{
Prepared by \\ Douglas D. Lee \\ Joseph F. Birdwell, Jr \\ Peter V. Bonnesen \\ Bruce A. Tomkins
}




\title{
DOCUMENT AVAILABILITY
}

Reports produced after January 1, 1996, are generally available free via the U.S. Department of Energy (DOE) Information Bridge:

Web site: http://www.osti.gov/bridge

Reports produced before January 1, 1996, may be purchased by members of the public from the following source:

\author{
National Technical Information Service \\ 5285 Port Royal Road \\ Springfield, VA 22161 \\ Telephone: 703-605-6000 (1-800-553-6847) \\ TDD: $703-487-4639$ \\ Fax: 703-605-6900 \\ E-mail: info@ntis.fedworld.gov \\ Web site: http://www.ntis.gov/support/ordernowabout.htm
}

Reports are available to DOE employees, DOE contractors, Energy Technology Data Exchange (ETDE) representatives, and International Nuclear Information System (INIS) representatives from the following source:

Office of Scientific and Technical Information

P.O. Box 62

Oak Ridge, TN 37831

Telephone: 865-576-8401

Fax: 865-576-5728

E-mail: reports@adonis.osti.gov

Web site: http://www.osti.gov/contact.html

This report was prepared as an account of work sponsored by an agency of the United States Government. Neither the United States government nor any agency thereof, nor any of their employees, makes any warranty, express or implied, or assumes any legal liability or responsibility for the accuracy, completeness, or usefulness of any information, apparatus, product, or process disclosed, or represents that its use would not infringe privately owned rights. Reference herein to any specific commercial product, process, or service by trade name, trademark, manufacturer, or otherwise, does not necessarily constitute or imply its endorsement, recommendation, or favoring by the United States Government or any agency thereof. The views and opinions of authors expressed herein do not necessarily state or reflect those of the United States Government or any agency thereof. 
Nuclear Science and Technology Division Chemical Sciences Division

\title{
Density Changes in the Optimized CSSX Solvent System
}

\author{
D. D. Lee \\ J. F. Birdwell, Jr. \\ P. V. Bonnesen \\ B. A. Tomkins
}

Date Published: November 2002

\author{
Prepared by the \\ OAK RIDGE NATIONAL LABORATORY \\ Oak Ridge, Tennessee 37831-6285 \\ managed by \\ UT-BATTELLE, LLC \\ for the \\ U.S. DEPARTMENT OF ENERGY \\ under contract DE-AC05-00OR22725
}





\section{CONTENTS}

Page

UST OF FIGURES

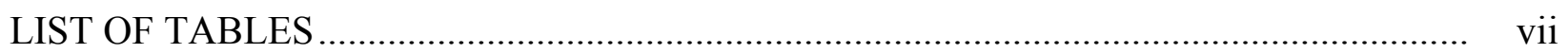

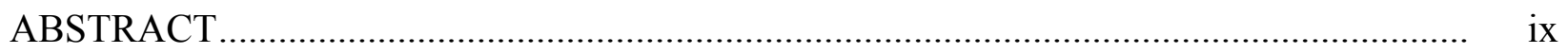

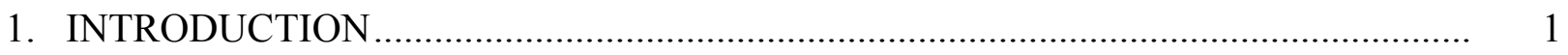

2. EXPERIMENTAL PROCEDURES ……………………........................................... 2

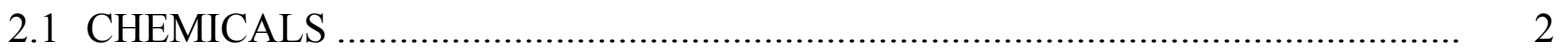

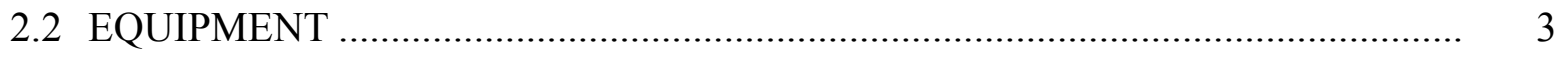

2.3 ANALYTICAL PROCEDURES .................................................................... 4

2.3.1 NMR Analyses...................................................................................... 4

2.3.2 HPLC Analyses......................................................................................... 4

2.4 EVALUATION OF EVAPORATION EFFECTS ………...................................... 5

2.5 EVALUATION OF CHEMICAL DEGRADATION EFFECTS................................ 6

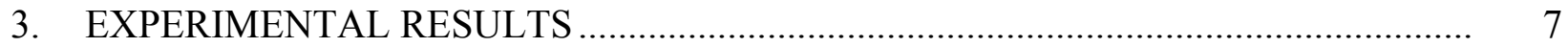

3.1 SOLVENT EVAPORATION ………………....................................................... 7

3.1.1 Evaporation-Produced Density Changes ......................................................... 7

3.1.2 Evaporation-Produced Viscosity Changes......................................................... 9

3.1.3 Solvent Composition Changes Produced by Evaporation ................................ 10

3.2 SOLVENT CHEMICAL INTERACTIONS ………………………………............. 19

4. DISCUSSION AND CONCLUSIONS ……………................................................ 26

4.1 CHANGES IN SOLVENT DENSITY ……………........................................... 26

4.2 EFFECTS OF CHANGES IN SOLVENT DENSITY ON SOLVENT COMPOSITION .......................................................................................... 27

4.3 EFFECTS OF SOLVENT DENSITY AND VISCOSITY ON CENTRIFUGAL CONTACTOR OPERATION ........................................................................ 31

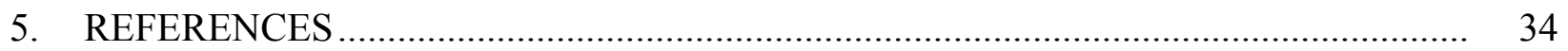




\section{LIST OF FIGURES}

Figure $\quad$ Page

1 Increase in CSSX solvent density as a result of evaporation at three temperatures.... 8

2 CSSX solvent density versus evaporation time at three temperatures..................... 8

3 Rate of CSSX solvent loss as a result of evaporation to flowing air....................... 9

4 Viscosity change for CSSX solvent from evaporation at three temperatures ............ 10

5 Correlation of viscosity and density for CSSX solvent during evaporation............. 11

6 Density of solvent versus the modifier concentration during evaporation at $45^{\circ} \mathrm{C} \ldots . . \quad 11$

7 Density of solvent versus the modifier concentration during evaporation at $35^{\circ} \mathrm{C} \ldots . . \quad 15$

8 Density of solvent versus the modifier concentration during evaporation at $25^{\circ} \mathrm{C} \ldots . . \quad 15$

9 Viscosity of solvent versus the modifier concentration during evaporation at $25^{\circ} \mathrm{C} . . \quad 16$

10 Solvent density versus the HPLC-and NMR-measured diluent loss ..................... 17

11 Solvent viscosity versus the HPLC-and NMR-measured diluent loss.................... 17

12 Solvent density versus the measured and calculated diluent loss at $25^{\circ} \mathrm{C} \ldots \ldots \ldots \ldots \ldots . . . . . . .18$

13 Solvent density versus the measured and calculated diluent loss at $35^{\circ} \mathrm{C} \ldots \ldots \ldots \ldots \ldots . . . . . . . .18$

14 Solvent density versus the measured and calculated diluent loss at $45^{\circ} \mathrm{C} \ldots \ldots \ldots \ldots \ldots . . . . . .19$

15 Density of CSSX solvent after contact with simulant, strip, and wash solutions ....... 20

16 Viscosity of CSSX solvent after contact with strip and wash solutions .................. 20

17 Modifier concentrations for the chemical interaction tests ................................. 24

18 Calix concentrations for the chemical interaction tests ..................................... 24

19 Ratio of Cs-7SB modifier to calix for the chemical interaction tests ...................... 25

20 Diluent loss in the chemical interaction tests .............................................. 25

21 Density versus modifier concentration for chemical interaction tests..................... 26 


\section{LIST OF TABLES}

Table

Page

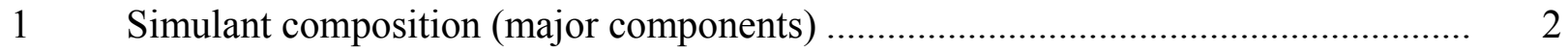

2 Materials for full simulant (added trace metals and organics) ............................... 3

$3 \quad$ Physical and chemical parameters of solvent evaporation at $25^{\circ} \mathrm{C} \ldots \ldots \ldots \ldots \ldots \ldots \ldots \ldots . . . \ldots \ldots$

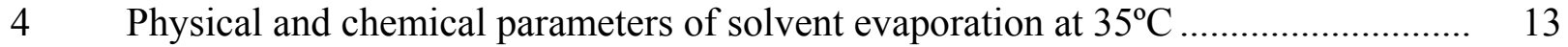

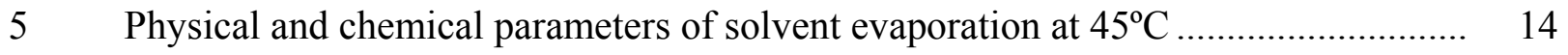

$6 \quad$ Chemical interaction test—solvent and simulant ......................................... 21

$7 \quad$ Chemical interaction test—-solvent and strip solution....................................... 22

$8 \quad$ Chemical interaction test—-solvent and wash solution..................................... 23

9 Comparison of solvent composition calculated from measured density and HPLC measurements for evaporation at $25^{\circ} \mathrm{C}$ starting from $1 \mathrm{~L}$ of solvent........................ 28

10 Comparison of solvent composition calculated from measured density and HPLC measurements for evaporation at $35^{\circ} \mathrm{C}$ starting from $1 \mathrm{~L}$ of solvent.......

11 Comparison of solvent composition calculated from measured density and HPLC measurements for evaporation at $45^{\circ} \mathrm{C}$ starting from $1 \mathrm{~L}$ of solvent

12 Correlation of calculated and measured values of Cs-7SB for density changes ........ 31

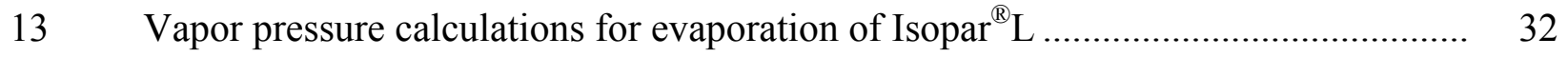

$14 \quad$ Solvent properties and predicted contactor throughputs ..................................... 32

15 Calculated D values for the extraction, scrub, and strip stages with increasing concentrations of modifier and calix. 


\begin{abstract}
Density increases in caustic-side solvent extraction (CSSX) solvent have been observed in separate experimental programs performed by different groups of researchers. Such changes indicate a change in chemical composition. Increased density adversely affects separation of solvent from denser aqueous solutions present in the CSSX process. Identification and control of factors affecting solvent density are essential for design and operation of the centrifugal contactors. The goals of this research were to identify the factors affecting solvent density (composition) and to develop correlations between easily measured solvent properties (density and viscosity) and the chemical composition of the solvent, which will permit real-time determination and adjustment of the solvent composition.

In evaporation experiments, virgin solvent was subjected to evaporation under quiescent conditions at 25,35 , and $45^{\circ} \mathrm{C}$ with continuously flowing dry air passing over the surface of the solvent. Density and viscosity were measured periodically, and chemical analysis was performed on the solvent samples. Chemical interaction tests were completed to determine if any chemical reaction takes place over extended contact time that changes the composition and/or physical properties. Solvent and simulant, solvent and strip solution, and solvent and wash solution were contacted continuously in agitated flasks. They were periodically sampled and the density measured (viscosity was also measured on some samples) and then submitted to the Chemical Sciences Division of Oak Ridge National Laboratory for analysis by nuclear magnetic resonance (NMR) spectrometry and high-performance liquid chromatography (HPLC) using the virgin solvent as the baseline.

Chemical interaction tests showed that solvent densities and viscosities did not change appreciably during contact with simulant, strip, or wash solution. No effects on density and viscosity and no chemical changes in the solvent were noted within experimental limits.

Evaporation test results showed that all solvents were evaporated to densities of greater than $0.90 \mathrm{~g} / \mathrm{cm}^{3}$. Viscosities increased from 3.5 to $>6.5 \mathrm{cP}$ as the densities increased. NMR and HPLC data indicate that diluent loss is the primary reason for density increase and that the ratio of BOBCalixC6 (referred to as calix) to Cs-7SB remained almost constant. Density and viscosity vary linearly with the loss of diluent and the increase in Cs-7SB concentration. Solvent viscosity and density are both sensitive indicators of the loss of diluent, especially when such loss is greater than $10 \%$. However, density is more reliable at low values for diluent loss. The ratio of Cs-7SB to calix appears relatively constant during evaporation to losses of more than $50 \%$ of the diluent. A simple density model accurately predicts the composition of the solvent when density is known. Density and viscosity increases can affect the throughput in the centrifugal contactors and, at the extreme, can cause complete loss of flow. The distribution coefficient can also increase, especially in the strip stage, causing the loss of the ability to strip extracted cesium from the solvent. These effects can be addressed by internal changes to the contactor and by adding additional stripping stages in processing. However, these changes are extremely difficult under remote operation and maintenance restrictions.
\end{abstract}




\section{INTRODUCTION}

The primary objective of the tests described in this work was to determine the cause of increases in solvent density over time in the caustic-side solvent extraction (CSSX) process. Solvent density increases of $2-10 \%$ have been observed in separate experimental programs performed by different groups of researchers. ${ }^{1-3}$ Solvent density changes indicate changes in chemical composition, and increased density adversely affect separation of solvent from denser aqueous solutions present in the CSSX process and also affect the operating characteristics of the centrifugal contactors. Therefore, identification, control, and mitigation of factors affecting solvent density are essential. ${ }^{4}$ A secondary objective of the experimental task was to develop a correlation between solvent properties (density and viscosity with chemical composition) that will permit real-time prediction and adjustment of the solvent composition. The extent to which the secondary objective is achieved will be determined by the number of factors found to affect solvent composition (as indicated by density change). If solvent composition change cannot be mitigated by control of process parameters (temperature, air sparge rates), the next-best mitigation is afforded by being able to adjust the solvent composition based on real-time density and/or viscosity measurement.

This report describes laboratory-scale evaluations of the optimized CSSX formulation. In one set of tests, virgin solvent was subjected to evaporation under quiescent conditions at 25,35 , and $45^{\circ} \mathrm{C}$ with continuously flowing dry air passing over the surface of the solvent in otherwise sealed bottles. Solvent density and viscosity were periodically measured on the solvents from the bottles, and samples were taken for chemical analysis. Chemical interaction tests were also completed in which the solvent and simulated supernatant, solvent and strip solution, and solvent and wash solution were contacted continuously in agitated flasks. The solvent in each flask was periodically sampled for chemical analysis and the density measured to determine if any chemical interaction takes place over extended contact time. Viscosity measurements were also made on some of the strip and wash samples.

The calixarene extractant was developed by researchers at Oak Ridge National Laboratory (ORNL) specifically for the CSSX application. The optimized solvent is comprised of $0.007 M$ calix[4]arene-bis(t-octyl benzo-crown-6) (aka BOBCalixC6), $0.75 M$ 1-(2,2,3,3tetrafluoropropoxy)-3-(4-sec-butylphenoxy)-2-propanol (Cs-7SB modifier), and $0.003 \quad M$ trioctylamine (TOA) in Isopar ${ }^{\mathbb{B}}$ L. $^{4}$ Previous evaluations of the optimized solvent included the determination of phase separation by gravity settling under conditions present in the extraction, scrubbing, and stripping sections of the CSSX cascade as well as measurement of solvent density and viscosity at several temperatures. Measurements of solvent surface tension and the interfacial tension of each solvent/simulant, solvent/scrub, and solvent/strip combination had been performed on candidate solvent compositions before finalizing the optimized solvent composition. Because very little difference was seen in the interfacial or surface tensions between the various formulations and the difficulty in determining either of these in real time on large batches of material, these tests were not part of the current testing. Results of the previous tests showed that all of the formulations performed the required separations and would perform in the contactors. The optimized solvent composition given above provided the best match between the measured properties and the performance criteria. 


\section{EXPERIMENTAL PROCEDURES}

\subsection{CHEMICALS}

The CSSX solvent is a blend of the organic materials described in Sect. 1 and was obtained from the Chemical Sciences Division at ORNL. Scrub $\left(0.05 \mathrm{MHNO} \mathrm{HN}_{3}\right)$ and strip $\left(0.001 \mathrm{M} \mathrm{HNO}_{3}\right)$ aqueous solutions were formulated by using $1.0 \mathrm{~N} \mathrm{HNO}_{3}$, procured from J. T. Baker Co. and diluted with water that had been deionized via a Barnstead Nanopure B filtration system. Sodium hydroxide solutions used to wash the solvent were formulated using a standard $0.1 \mathrm{~N}$ sodium hydroxide solution (ACS reagent grade, procured from the J. T. Baker Co.). Savannah River Site (SRS) waste supernatant simulant was formulated according to SRS procedure WSRC-RP-2000-00361, Rev. 0, but the composition listed in that document for "average" SRS supernatant simulant was adjusted slightly as shown in Table 1 to match the new average simulant. The cesium concentration in the simulant batch used in testing was $0.000143 M$. The simulant was prepared by first combining the ingredients (except for the cesium and silica) shown in Table 1. These were added along with the metals and organics shown in Table 2 to make the complete simulant. After all the materials in Tables 1 and 2 were combined and allowed to age over a 3-day period, the simulant was filtered through a $0.45-\mu \mathrm{m}$ Gelman polypropylene groundwater filter to remove any precipitates formed. After filtration, the simulant remained clear during all remaining testing.

Table 1. Simulant composition (major components)

\begin{tabular}{|c|c|c|c|c|c|}
\hline Component & $\begin{array}{c}\text { Avg SRS }^{a} \\
\text { Simulant } \\
(M)\end{array}$ & 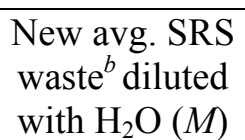 & $\begin{array}{l}\text { Compound } \\
\text { used }\end{array}$ & Mol Wt & $\begin{array}{c}\text { Mass,for } \\
\text { new avg. } \\
\text { (g/L) }\end{array}$ \\
\hline $\mathrm{Na}^{+}$ & 5.6 & 5.6 & & & \\
\hline $\mathrm{Cs}^{+}$ & 0.00014 & 0.000143 & $\mathrm{CsCl}$ & 168.37 & 0.024077 \\
\hline $\mathrm{K}^{+}$ & 0.015 & 0.0146 & $\mathrm{KNO}_{3}$ & 101.10 & 1.47606 \\
\hline $\mathrm{OH}^{-}$ & 1.91 & 2.086 & $\mathrm{NaOH}$ & 40.00 & 81.56 \\
\hline $3^{-}$ & 2.14 & 2.039 & $\mathrm{NaNO}_{3}$ & 84.99 & 173.295 \\
\hline $\mathrm{NO}_{2}^{-}$ & 0.52 & 0.494 & $\mathrm{NaNO}_{2}$ & 69.00 & 34.086 \\
\hline $\mathrm{AlO}_{2}^{-}$ & 0.31 & 0.289 & $\mathrm{Al}\left(\mathrm{NO}_{3}\right)_{3} \cdot 9 \mathrm{H}_{2} \mathrm{O}$ & 375.14 & 108.415 \\
\hline $\mathrm{CO}_{3}{ }^{2-}$ & 0.16 & 0.147 & $\mathrm{Na}_{2} \mathrm{CO}_{3} \cdot \mathrm{H}_{2} \mathrm{O}$ & 124.01 & 18.2295 \\
\hline $\mathrm{SO}_{4}{ }^{2-}$ & 0.15 & 0.137 & $\mathrm{Na}_{2} \mathrm{SO}_{4}$ & 142.04 & 19.4595 \\
\hline $\mathrm{Cl}^{-}$ & 0.025 & 0.025 & $\mathrm{NaCl}$ & 58.44 & 1.4610 \\
\hline $\mathrm{F}^{-}$ & 0.032 & 0.030 & $\mathrm{NaF}$ & 41.99 & 1.2597 \\
\hline $\mathrm{PO}_{4}{ }^{3-}$ & 0.010 & 0.007 & $\mathrm{Na}_{2} \mathrm{HPO}_{4} \cdot 7 \mathrm{H}_{2} \mathrm{O}$ & 268.09 & 1.8766 \\
\hline $\mathrm{C}_{2} \mathrm{O}_{4}{ }^{2-}$ & 0.008 & 0.018 & $\begin{array}{c}\mathrm{Na}_{2} \mathrm{C}_{2} \mathrm{O}_{4} \\
\text { (Sodium Oxalate) }\end{array}$ & 134.00 & 2.412 \\
\hline $\mathrm{SiO}_{3}{ }^{2-}$ & 0.004 & 0.003 & $\mathrm{Na}_{2} \mathrm{SiO}_{3} \cdot 9 \mathrm{H}_{2} \mathrm{O}$ & 284.20 & 0.8526 \\
\hline $\mathrm{MoO}_{4}{ }^{2-}$ & 0.0002 & 0.0002 & $\mathrm{Na}_{2} \mathrm{MoO}_{4} \cdot 2 \mathrm{H}_{2} \mathrm{O}$ & 241.95 & 0.04839 \\
\hline
\end{tabular}

${ }^{a}$ R. Jacobs, Bases, Assumptions, and Results of the Flowsheet Calculations for the Short List Salt Disposition Alternatives, WSRC-RP-98-00168,Rev. 1, Westinghouse Savannah River Company, Aiken, South Carolina, May, 1998.

${ }^{b}$ R. A. Dimenna et al., Bases, Assumptions, and Results of the Flowsheet Calculations for the Decision Phase Salt Disposition Alternatives, WSRC-RP-99-00006, Rev. 3, Westinghouse Savannah River Company, Aiken, South Carolina, May, 2001. 
Table 2. Materials for full simulant (added trace metals and organics)

\begin{tabular}{|c|c|c|c|c|}
\hline Component & $\begin{array}{c}\text { Concentration } \\
\text { in simulant } \\
(M)\end{array}$ & $\begin{array}{c}\text { Compound } \\
\text { used }\end{array}$ & Molecular weight & $\begin{array}{l}\text { Mass } \\
(\mathrm{g} / \mathrm{L})\end{array}$ \\
\hline $\mathrm{Cu}^{2+}$ & $2.27 \times 10^{-5}$ & $\mathrm{CuSO}_{4} \cdot 5 \mathrm{H}_{2} \mathrm{O}$ & 249.68 & 0.00566 \\
\hline $\mathrm{Cr}^{6+}$ & $1.44 \times 10^{-3}$ & $\mathrm{Na}_{2} \mathrm{CrO}_{4}$ & 161.97 & 0.2336 \\
\hline $\mathrm{Zn}^{2+}$ & $1.22 \times 10^{-4}$ & $\mathrm{Zn}\left(\mathrm{NO}_{3}\right)_{2} \cdot 6 \mathrm{H}_{2} \mathrm{O}$ & 297.47 & 0.0364 \\
\hline $\mathrm{Pb}^{2+}$ & $1.01 \times 10^{-5}$ & $\mathrm{~Pb}\left(\mathrm{NO}_{3}\right)_{2}$ & 331.2 & 0.00336 \\
\hline $\mathrm{Fe}^{3+}$ & $2.58 \times 10^{-5}$ & $\mathrm{Fe}\left(\mathrm{NO}_{3}\right)_{3} \cdot 9 \mathrm{H}_{2} \mathrm{O}$ & 404.00 & 0.01042 \\
\hline $\mathrm{Sn}^{2+}$ & $2.02 \times 10^{-5}$ & $\mathrm{SnCl}_{2} \cdot 2 \mathrm{H}_{2} \mathrm{O}$ & 225.63 & 0.00456 \\
\hline $\mathrm{Hg}^{2+}$ & $2.49 \times 10^{-7}$ & $\mathrm{Hg}\left(\mathrm{NO}_{3}\right)_{2} \cdot \mathrm{H}_{2} \mathrm{O}$ & 342.61 & 0.0000854 \\
\hline $\mathrm{Rh}^{3+}$ & $2.04 \times 10^{-6}$ & $\mathrm{Rh}\left(\mathrm{NO}_{3}\right)_{3} \cdot 2 \mathrm{H}_{2} \mathrm{O}$ & 324.95 & 0.000663 \\
\hline $\mathrm{Pd}^{2+}$ & $3.85 \times 10^{-6}$ & $\mathrm{Pd}\left(\mathrm{NO}_{3}\right)_{2}$ & 230.43 & 0.000888 \\
\hline $\mathrm{Ag}^{+}$ & $9.27 \times 10^{-8}$ & $\mathrm{AgNO}_{3}$ & 169.87 & 0.0000157 \\
\hline $\mathrm{Ru}^{3+}$ & $8.11 \times 10^{-6}$ & $\mathrm{RuCl}_{3}$ & 207.43 & 0.00168 \\
\hline ТPB & $1.88 \times 10^{-6}$ & Tributylphosphate & 266.32 & 0.0005 \\
\hline DBP & $1.19 \times 10^{-4}$ & Dibutylphosphate & 210.21 & 0.025 \\
\hline MBP & $1.62 \times 10^{-4}$ & Monobutylphosphate & 154.10 & 0.025 \\
\hline n-Butanol & $2.7 \times 10^{-5}$ & $\mathrm{C}_{4} \mathrm{H}_{9} \mathrm{OH}$ & 74.12 & 0.002 \\
\hline $\mathrm{CHO}_{2}^{-}$ & $3.33 \times 10^{-2}$ & $\begin{array}{c}\mathrm{NaCHO}_{2} \\
\text { (sodium formate) }\end{array}$ & 68.01 & 1.5 \\
\hline TMA & $1.69 \times 10^{-4}$ & Trimethylamine & 59.11 & 0.01 \\
\hline
\end{tabular}

\subsection{EQUIPMENT}

Three refrigerated water baths (two VWR model 13270-615 circulation baths filled with distilled water and a Brinkman Lauda RK 20 circulation bath that also was used to regulate the temperature of the shaker bath) were used to control the evaporation and chemical contact temperatures. A six-place Labline shaker bath set at about 140 oscillations per min was used to contact the solvent with aqueous solutions. A thermometer accurate to $0.1^{\circ} \mathrm{C}$ (LaPine 398-12-53) was used to measure the temperatures of the baths and other apparatus. A temperature recorder (Yokogawa six-pen temperature recorder) with Type $\mathrm{K}$ thermocouples was used to monitor and record the temperatures of the water baths and the shaker bath during the experimental tests. Nine $250-\mathrm{mL}$ Teflon narrow-mouth bottles were used for the evaporation tests. Each bottle was equipped with a gas supply, a 0 - to $2-$ scfh rotameter with control valve, and a gas discharge line. The air supply came from cylinders of breathing air routed through each rotameter, which were set at about $0.5-0.6 \mathrm{scfh}(235-300 \mathrm{~mL} / \mathrm{min})$. Six 250-mL glassstoppered Erlenmeyer flasks were used for the chemical contact tests.

The solvent densities were measured using procedures based on American Society for Testing Materials (ASTM) D891 ${ }^{5}$ and ASTM D1429, ${ }^{6}$ using 50-mL, class A borosilicate glass volumetric flasks with ground-glass stoppers and 1- and 2-mL class A pycnometers. Calibration of the volumetric flasks and pycnometers for density measurements was performed based on ASTM E542. ${ }^{7}$ A Mettler AE263 analytical balance (S/N J19097) capable of measuring to $0.1 \mathrm{mg}$ was used to weigh the flasks and pycnometers. National Institute of Standards and Technology (NIST)-based test weights were used to check the balance calibration. Before use, the flasks were cleaned by using three rinses with tap water, three rinses with deionized water, two rinses with ethanol, and two rinses with acetone, followed by drying with argon gas or air. 
Each flask was filled using a polyethylene transfer pipette to just below the line. It was then adjusted to the line with a small transfer pipette after the flask had come to temperature in the water bath. The actual volume of each flask and pycnometer was calculated from the weight of the water contained at $25^{\circ} \mathrm{C}$, and the volume at other test temperatures was calculated according to ASTM E542. The calculated volume was used in subsequent density determinations of the solvent at each temperature.

The viscosity of the solvents was measured at $25^{\circ} \mathrm{C}$ (using procedures adapted from ASTM D $2196^{8}$ and the Brookfield viscometer operating instructions ${ }^{9}$ ). The determinations were made using a Brookfield rotational viscometer, Model LVTDV-II, serial number D15869, with a UL adapter. The UL adapter (a large-diameter spindle in a cylindrical container just slightly larger in diameter than the spindle) is used for measuring low-viscosity liquids (liquids with viscosities between 1 and $20 \mathrm{cP}$ ). The adapter with spindle holds $16 \mathrm{~mL}$ of sample for measurement. A water jacket on the UL adapter was heated and cooled by a VWR model 13270-615 circulation bath. (Water was circulated through the adapter using the bath circulation pump.) A LaPine model 398-12-53 thermometer was immersed in the water bath for temperature measurement. (There is no room in the UL adapter for a thermometer.) The spindle speed was set to give a torque percent reading in the middle or upper portion of the scale. During the tests, no conditions required a speed lower than $60 \mathrm{rpm}$, except for the last measurement on solvent flask 1 as it underwent evaporation at $25^{\circ} \mathrm{C}$.

Each measurement was begun by adding $16 \mathrm{~mL}$ of solvent to the UL adapter, installing it on the viscometer, and starting the spindle rotation at $60 \mathrm{rpm}$ with the setting on the temperature bath at $25^{\circ} \mathrm{C}$. After the temperature had stabilized for several minutes, the viscosity of the sample was measured. The solvent was then returned to the test bottle or flask. Percent torque, viscosity, and shear rate measurements were taken for solvent samples from each bottle or flask.

\subsection{ANALYTICAL PROCEDURES}

\subsubsection{NMR Analyses}

Nuclear magnetic resonance (NMR) spectra were obtained on a Bruker Avance 400 wide-bore spectrometer. Samples were prepared by placing $100 \mu \mathrm{L}$ of the solvent in the NMR tube and adding $650 \mu \mathrm{L}$ of deuterochloroform containing a known amount of hexamethylbenzene (HMB) as an integration standard. The ratio of the integral for the proton resonance for the terminal proton on the $-\mathrm{CF}_{2} \mathrm{CF}_{2} \mathrm{H}$ group of the modifier to the integral for the HMB peak was then measured. The time-zero sample (virgin solvent) was normalized to $0.75 \mathrm{M}$ modifier (the starting concentration of virgin solvent); the modifier concentration was then calculated for the other samples based on this ratio (which increased). From the new modifier concentration, the corresponding volume of solvent and the amount of diluent lost were next calculated. The error analysis gave the uncertainty in the modifier molarity of about $\pm 10 \%$. Sources of error include the assumption of $0.75 \mathrm{M}$ modifier concentration in the virgin solvent and slight differences in the pipetted volumes of sample due to wetting of the pipette tips by the solvent. The results were able to track the loss of diluent through each sample series and showed about $50 \%$ loss of diluent in the last samples of each series.

\subsubsection{HPLC Analyses}

Samples were prepared by first diluting $100 \mu \mathrm{L}$ of the original sample prepared to a final volume of $1 \mathrm{~mL}$ with isopropanol. All samples were then analyzed via high-performance liquid 
chromatography (HPLC), using a Hewlett-Packard Model 1090 chromatograph equipped with an automatic sampler (maximum of 100 individual samples, maximum injection volume of $250 \mu \mathrm{L}$ ), ternary solvent gradient capability, and a diode array detector (wavelength range of 190-600 nm). A polystyrene divinylbenzene reverse-phase (PRP-1) column $(150 \times 4.1 \mathrm{~mm})$, packed with $10-\mu \mathrm{m}$-diameter particles (100- $\AA$ porosity), a product of the Hamilton Co. (Reno, $\mathrm{NV}$ ), was used for all determinations. The analytes were eluted isocratically from the column using a $60 / 40(\mathrm{v} / \mathrm{v})$ mixture of isopropanol/acetonitrile at a flow rate of $1.00 \mathrm{~mL} / \mathrm{min}$. The sample analysis time was 5 minutes per sample; each sample was analyzed in duplicate. Both the analytical column and the solvent were heated to $40^{\circ} \mathrm{C}$ using the internal column oven. A $5-\mu \mathrm{L}$ aliquot was withdrawn from a total sample volume of $1 \mathrm{~mL}$ for each determination performed.

The analytes BOBCalixC6 and Cs-7SB modifier were qualified using the wavelengths 226 and $254 \mathrm{~nm}$, respectively, set using the diode array detector. Each analyte was calibrated using six independent standards prepared in isopropanol/Isopar ${ }^{\circledR} \mathrm{L}$, each of which was analyzed in duplicate. The calibration ranges for BOBCalixC6 and Cs-7SB modifier were 0.175 to $1.75 \mathrm{~m} M$ and 18.75 to $187.5 \mathrm{~m} M$, respectively. Sets of calibration standards were prepared fresh daily in 2-mL automatic sampler vials, using digital pipettors to dispense the stock solution (7 $\mathrm{m} M$ BOBCalixC6 and $750 \mathrm{~m} M$ Cs-7SB modifier in Isopar ${ }^{\circledR} \mathrm{L}$ ). The measured integrated peak areas were fit to a linear least-squares line, where the coefficient of determination, $\mathrm{r}^{2}$, exceeded 0.997 for each analyte. Also, the time-zero (virgin-solvent) value was averaged from 14 runs.

\subsection{EVALUATION OF EVAPORATION EFFECTS}

Groups of three bottles were purged with dry air through a tube extending about $3 \mathrm{~cm}$ into the top of the bottle at controlled temperatures of 25,35 , and $45^{\circ} \mathrm{C}$. The air exited the bottle through a second tube flush with the top of the bottle. The flow of air was controlled at a nominal rate of $250-300 \mathrm{~mL} / \mathrm{min}$. Temperature control was achieved by submerging the test bottles in controlled-temperature baths. Dry air from breathing air cylinders was used for the evaporation tests. The test bottles were $5.64 \mathrm{~cm}$ in diameter, with $100 \mathrm{~mL}$ of solvent initially placed into each. With the solvent in place, the liquid height was about $4 \mathrm{~cm}$. The gas space in each bottle was initially about $7.6 \mathrm{~cm}$. The bottles were vented to a laboratory hood.

Each of the bottles was first weighed, then filled with about $100 \mathrm{~mL}$ of fresh solvent, reweighed, and the air supply attached. The bottles were then placed into the three different temperature water baths and allowed to come to thermal equilibrium before the air purge was initiated. After various time intervals, the airflow was discontinued and the bottles removed from the bath. The exterior of each bottle was dried, and each bottle was weighed to determine the mass lost during evaporation. Next, $0.5-$ to $1-\mathrm{mL}$ samples were collected from each bottle. The volumetric flasks for density determinations were filled and placed in the $25^{\circ} \mathrm{C}$ temperature bath to reach equilibrium; solvent was then added or removed to correct to the line. The flasks were then removed from the bath, dried, and weighed. Next, $16 \mathrm{~mL}$ from the volumetric flask was placed in the viscometer cup and the viscosity of each was measured at $25^{\circ} \mathrm{C}$. The density and viscosity samples were returned to the appropriate sample bottles. The bottles were then reweighed, returned to the water baths, and air purging resumed.

Sampling and testing was repeated at $24,48,120,168,216,272\left(45^{\circ} \mathrm{C}\right)$ or $284(25$ and $35^{\circ} \mathrm{C}$ ), 356, 452, and $668 \mathrm{~h}$. Although sampling at $25^{\circ} \mathrm{C}$ was continued for the full range of time intervals, sampling performed at 35 and $45^{\circ} \mathrm{C}$ was discontinued after 272 and 284 hours, respectively. The samples were submitted for composition analysis by NMR and HPLC. 


\subsection{EVALUATION OF CHEMICAL DEGRADATION EFFECTS}

The purpose of these tests was to determine performance of the optimized CSSX solvent under conditions approximating those present in the extraction, stripping, and solvent washing sections of the CSSX cascade. As shown in Tables 1 and 2, the simulant contained salts, metals, and organic compounds, as well as a cesium concentration of $0.00014 \mathrm{M}$. Prior to testing for chemical interactions with strip and wash solutions, the solvent was preequilibrated under extraction and scrub solutions or under extraction, scrub, and strip conditions. Extractioncondition test solvent was contacted only under extraction conditions. For extraction, $148.6 \mathrm{~mL}$ of a solution-composed of $35 \mathrm{~mL}$ solvent, $106.6 \mathrm{~mL}$ simulant, and $7.0 \mathrm{~mL}$ of scrub solution - was added to each of two flasks (flasks 1 and 2).

The solvent for strip and wash contact was prepared by first contacting three batches of 658.3-mL solution [141.7 mL solvent, $488.3 \mathrm{~mL}$ simulant, $28.3 \mathrm{~mL}$ scrub solution $\left.\left(0.05 \mathrm{MHNO}_{3}\right)\right]$. It was shaken in a volumetric flask for $20 \mathrm{~s}$, held still for $10 \mathrm{~s}$, shaken for $20 \mathrm{~s}$, held still for $10 \mathrm{~s}$ and shaken again for $20 \mathrm{~s}$. The solvent was allowed to separate and was then withdrawn for treatment with scrub solution. Then $420 \mathrm{~mL}$ of solvent and $84 \mathrm{~mL}$ of scrub solution [organic-to-aqueous (O:A) volume ratio under scrub conditions is 5.0] was contacted as above, shaken in a volumetric flask for $20 \mathrm{~s}$, held still for $10 \mathrm{~s}$, shaken for $20 \mathrm{~s}$, held for $10 \mathrm{~s}$ and shaken again for $20 \mathrm{~s}$. After separation, $104.2 \mathrm{~mL}$ of solvent and $20.8 \mathrm{~mL}$ of strip solution $\left(0.001 \mathrm{M} \mathrm{HNO}_{3}\right)$ was placed into flasks 3 and 4 . (The O:A volume ratio under scrub conditions is 5.0).

After treatment with the scrub solution, solvent for the wash contact testing was further contacted with strip solution. A flask was filled with $216 \mathrm{~mL}$ of the solvent left from the scrub contacts described above and $43.2 \mathrm{~mL}$ of strip solution. The flask was contacted as above, shaken for $20 \mathrm{~s}$, held still for $10 \mathrm{~s}$, shaken for $20 \mathrm{~s}$, held still for $10 \mathrm{~s}$ and shaken again for $20 \mathrm{~s}$. After phase separation, $104.2 \mathrm{~mL}$ of solvent and $20.8 \mathrm{~mL}$ of wash solution $(0.01 \mathrm{M} \mathrm{NaOH})$ were added to flasks 5 and 6. (The O:A volume ratio under wash conditions is 5.0.) Then all six flasks were sealed with ground-glass stoppers and placed on the shaker table which was submerged under water. The shaker oscillations were set at 140 per minute and the temperature control of the shaker was set at $25^{\circ} \mathrm{C}$.

The samples were agitated continuously for $24 \mathrm{~h}$. The agitation was then stopped, and samples were collected from all flasks for analysis. The densities of the samples were also measured. For samples 1 and 2, the extraction contacts, 1-mL pycnometers were used for density measurements. During the density measurement on sample 3 at $96 \mathrm{~h}$, the $50-\mathrm{mL}$ volumetric flask was broken. To compensate for the lost solvent volume, $10 \mathrm{~mL}$ of the aqueous phase was also removed from sample 3 to maintain the correct O:A ratio. Thereafter, a 2-mL pycnometer was used to measure the density on sample 3 . The remaining sample volumes were returned to their source flasks after the appropriate volumes of the aqueous phase were removed from each flask so that the original volume proportions were maintained. The agitation of all samples was then resumed. The sample collection and analysis were repeated after 96, 144, 192, $260,336,432$, and $650 \mathrm{~h}$ of agitation at controlled temperature. The solvent viscosity of some of the samples was also measured as described above.

After $24 \mathrm{~h}$, the temperature control for the shaker was found to have failed. The temperature remained at $23.5-24^{\circ} \mathrm{C}$, instead of the intended $25^{\circ} \mathrm{C}$. During the next $72 \mathrm{~h}$, the temperature dipped to as low as $21.5^{\circ} \mathrm{C}$ for a short period but remained between 22.5 and $23.5^{\circ} \mathrm{C}$ during most of the time. After $96 \mathrm{~h}$, a copper heat-exchange tube was placed in the shaker below the water level and connected to the circulation pump of the $25^{\circ} \mathrm{C}$ water bath. After this 
adaptation, the temperature of the shaker bath was maintained at $24.9-25.0^{\circ} \mathrm{C}$ for the rest of the test period. After $160 \mathrm{~h}$, the holder for flask 4 had broken and the flask was lying on its side on the shaker table. The flask stopper had not come out, so flask 4 replaced flask 3 in the shaker. (Flask 3 was removed until a replacement flask holder could be obtained the following day.) The flask holder was replaced when the $192 \mathrm{~h}$ samples were obtained, and flask 3 was returned to shaking with the other samples. The holder for flask 6 broke after about $530 \mathrm{~h}$, and that flask was removed from the shaker and remained unshaken until the final sampling at $650 \mathrm{~h}$.

\section{EXPERIMENTAL RESULTS}

\subsection{SOLVENT EVAPORATION}

\subsubsection{Evaporation-Produced Density Changes}

The evaporation of the solvent at three different temperatures with air flowing over a quiescent surface depleted the solvent of diluent. Measurements of density and viscosity and the NMR and HPLC measurements of the concentrations of both the calix and the Cs-7SB indicated that the light Isopar ${ }^{\circledR} \mathrm{L}$ was disappearing. The Cs-7SB has a density of about $1.197 \mathrm{~g} / \mathrm{cm}^{3}$ at $25^{\circ} \mathrm{C}$ while that of the Isopar ${ }^{\circledR} \mathrm{L}$ is about $0.77 \mathrm{~g} / \mathrm{cm}^{3}$. The vapor pressure of the Isopar ${ }^{\circledR} \mathrm{L}$ is $0.8 \mathrm{~mm} \mathrm{Hg}$ at $20^{\circ} \mathrm{C}$ while that for the Cs-7SB is $0.000135 \mathrm{~mm} \mathrm{Hg}$ at $62.4{ }^{\circ} \mathrm{C}$. (It was too low to measure at any lower temperature. $)^{10}$ This difference is more than three orders of magnitude. The TOA also has a very low vapor pressure, as evidenced by its boiling point of $365-367^{\circ} \mathrm{C}$ compared with that of the Cs-7SB modifier (about $375-380^{\circ} \mathrm{C}$. Thus, its evaporation rate would be comparable to that of the Cs-7SB modifier, and there was no evidence that the modifier was evaporating. The calix is a solid that is dissolved in the Isopar ${ }^{\mathbb{R}} \mathrm{L}$ and the modifier; therefore, the calix would not be expected to evaporate either.

The evaporations were conducted at three different temperatures to determine if anything occurred at higher temperatures that was not expected at the normal operating temperatures planned for the CSSX system and to ascertain whether temperature control could mitigate diluent loss. Temperature excursions could be the result of upsets or conditions in storage locations. The results of the evaporations are shown in the next several figures and tables. Figure 1 shows the increase in density in each of the bottles after each segment of time. The differences in the density changes between the bottles in each set are primarily the result of slight differences in the rate of airflow through the bottle. For example, the flow rates through bottles 1, 2, and 3 were $\sim 305, \sim 250$, and $\sim 230 \mathrm{~mL} / \mathrm{min}$, respectively. The density differences for the first $24-\mathrm{h}$ period were about $0.3-0.4 \%$, much greater than the measurement error of about $0.05 \%$, indicating an actual change in density. Changes during the first day were very similar for all of the bottles; however, at the two higher temperatures, the changes were noticeably larger. During longer evaporation periods, the changes between the temperatures were more pronounced. As indicated in the differences between the first three bottles, the airflow rate can have a significant effect on the evaporation rate, as expected.

Figure 2 shows the density change as a function of evaporation time (i.e., gas purge duration). The effect of variations in gas flow rate on density became more apparent as the evaporation time increased. Flow rate variations occurred when air cylinders were changed, as a result of differences in pressure regulator settings. These variations produced barely noticeable changes in rotameter readings but did result in the slight changes in the sample loss rates seen in Fig. 3. Other changes resulted when individual rotameters were readjusted to try to maintain 


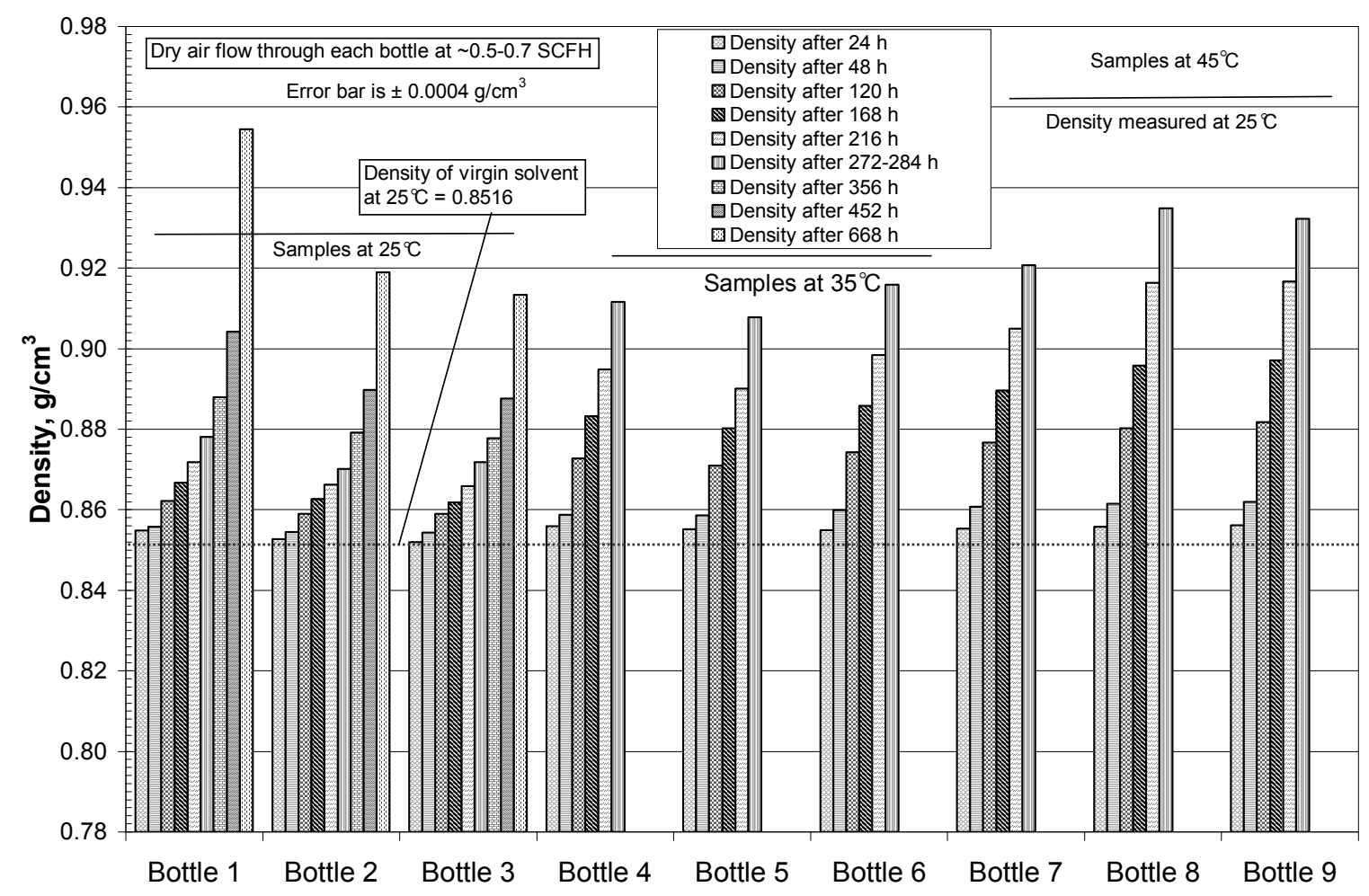

Fig. 1. Increase in CSSX solvent density as a result of evaporation at three temperatures.

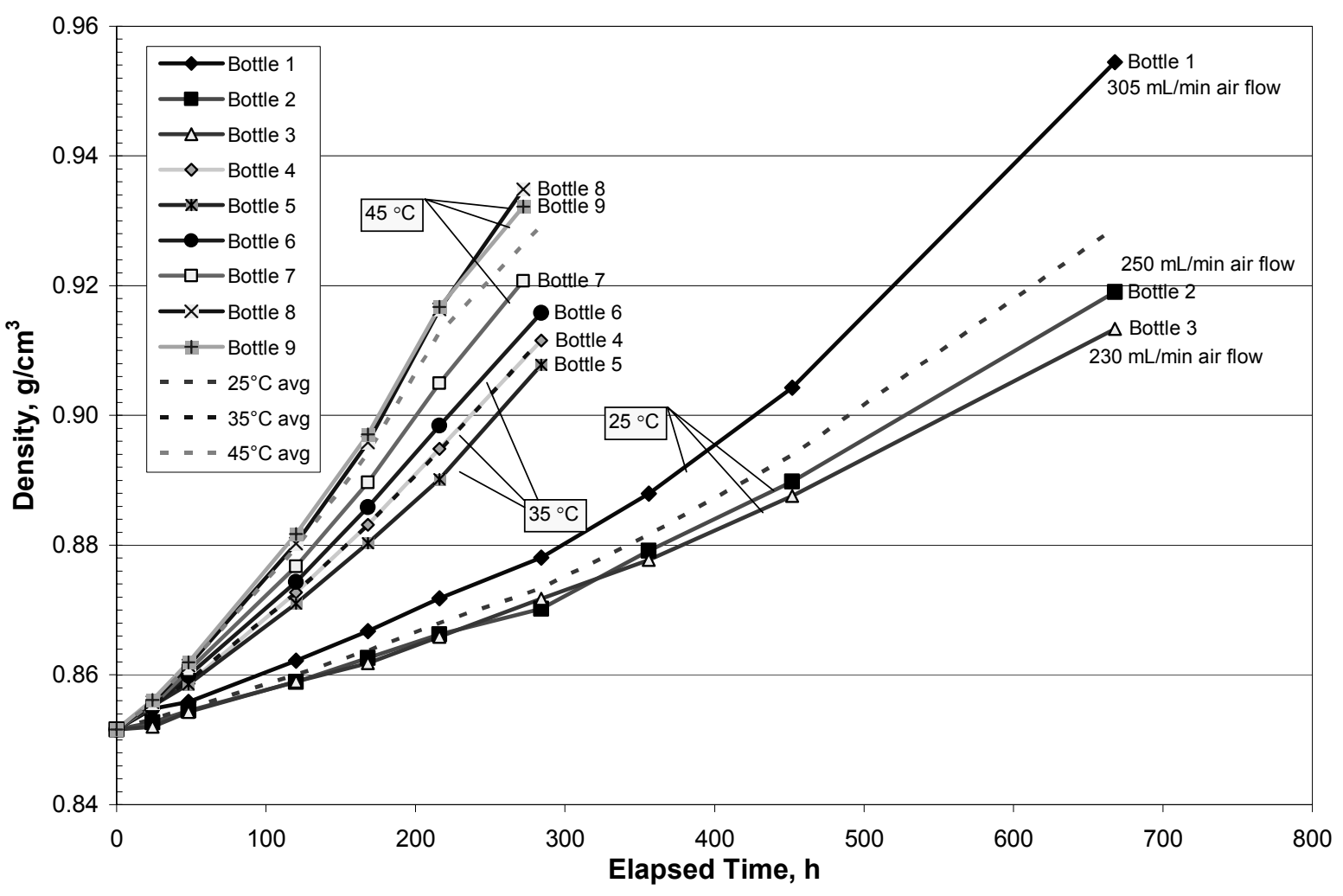

Fig. 2. CSSX solvent density versus evaporation time at three temperatures. 
the original flow rate after changing air cylinders. When evaporation ended, the density of the solvent was about $0.91 \mathrm{~g} / \mathrm{cm}^{3}$ or higher for all bottles. This equates to about a $45-50 \% \operatorname{loss}$ in the Isopar ${ }^{\circledR} \mathrm{L}$, if the diluent is the only component lost from the solvent.

In Fig. 3, the evaporation is presented in a graph of the evaporation rate during each period. These graphs show that increases in the rates at elevated temperatures are significant for similar airflow rates. The graph also shows the tendency for a decrease in evaporation rates as the solvent becomes depleted in the Isopar ${ }^{\circledR} \mathrm{L}$, especially above $30 \%$ loss in the diluent.

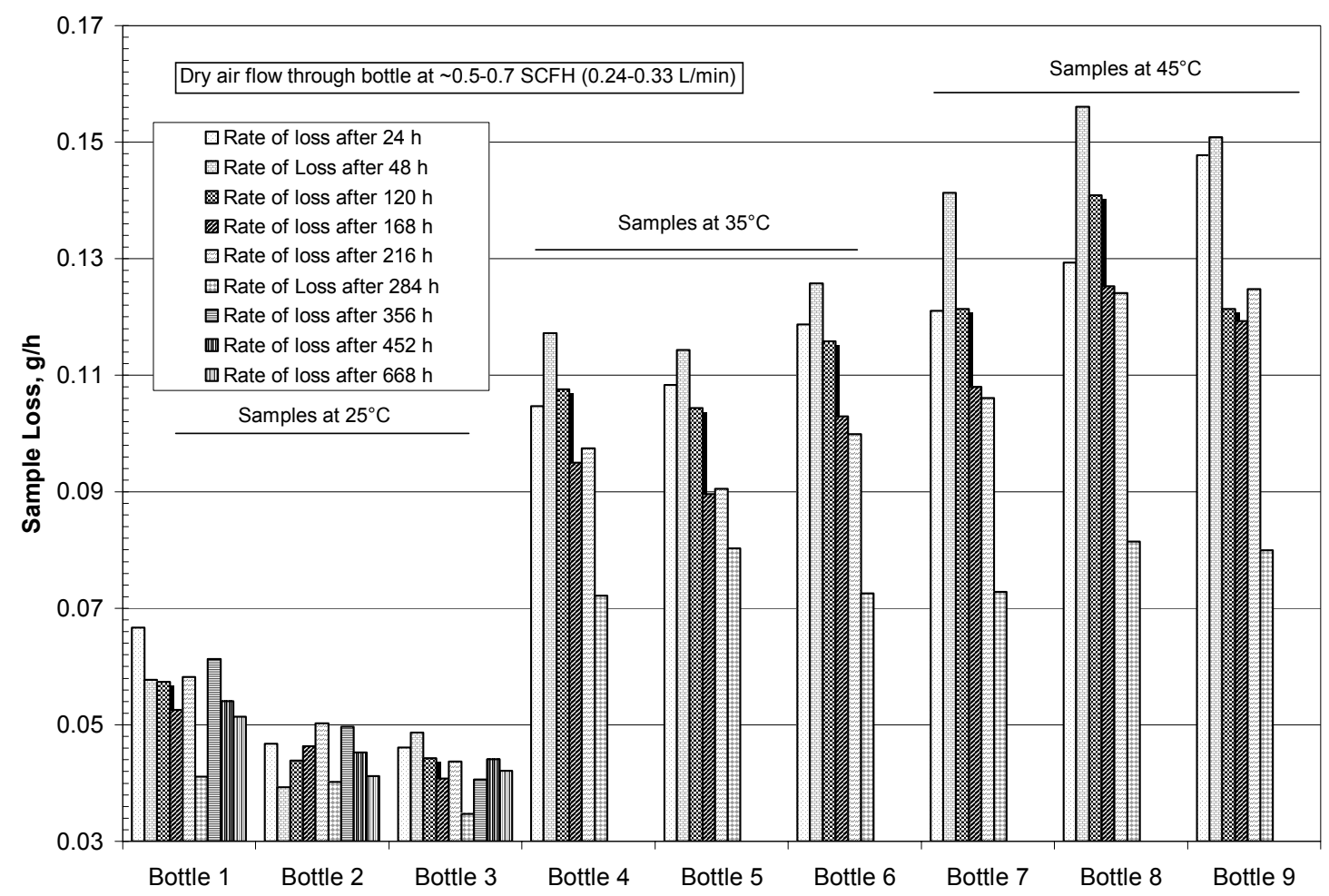

Fig. 3. Rate of CSSX solvent loss as a result of evaporation to flowing air.

\subsubsection{Evaporation-Produced Viscosity Changes}

Viscosity is also affected as the Isopar ${ }^{\circledR} \mathrm{L}$ is lost from the solvent. The increase in viscosity with a decrease in the diluent concentration (and the corresponding increase in the Cs7SB concentration) can be seen in Fig. 4. It is immediately apparent that the viscosity increases rapidly as the Isopar ${ }^{\circledR} \mathrm{L}$ is lost. The increase is especially noticeable in bottle 1 . During the last evaporation period, the loss of diluent approached $60 \%$, and there was a very pronounced increase in viscosity compared with that noted for the other bottles during the same time period. The viscosity almost doubled during the evaporations at 35 and $45^{\circ} \mathrm{C}$ as the evaporation approached the loss of $50 \%$ of the diluent. In the evaporation at $25^{\circ} \mathrm{C}$, the viscosity more than tripled after $60 \%$ loss of diluent in bottle 1 . Figure 5 shows the correlation between viscosity, $\mu$, and density, $\rho$, for the solvent as it loses the Isopar $^{\circledR} \mathrm{L}$ during evaporation at all three temperatures. The correlation is a power law with the following form with correlation coefficient, $\mathrm{R}^{2}$ :

$$
\mu=18.066 \cdot(\rho)^{10.351}, \quad \mathrm{R}^{2}=0.9947
$$


Over narrower density ranges, linear correlations may be used. For example, for the range of densities between 0.852 and 0.875 :

$$
\mu=44.198 \cdot \rho-34.177, \quad \mathrm{R}^{2}=0.9537
$$

For densities between 0.88 and 0.94 :

$$
\mu=88.735 \cdot \rho-73.884, \quad \mathrm{R}^{2}=0.9723
$$

The gradually increasing slope of the curve means that at lower losses of diluent, the density changes at a greater rate than the viscosity and that at the higher losses, the viscosity changes at a greater rate.

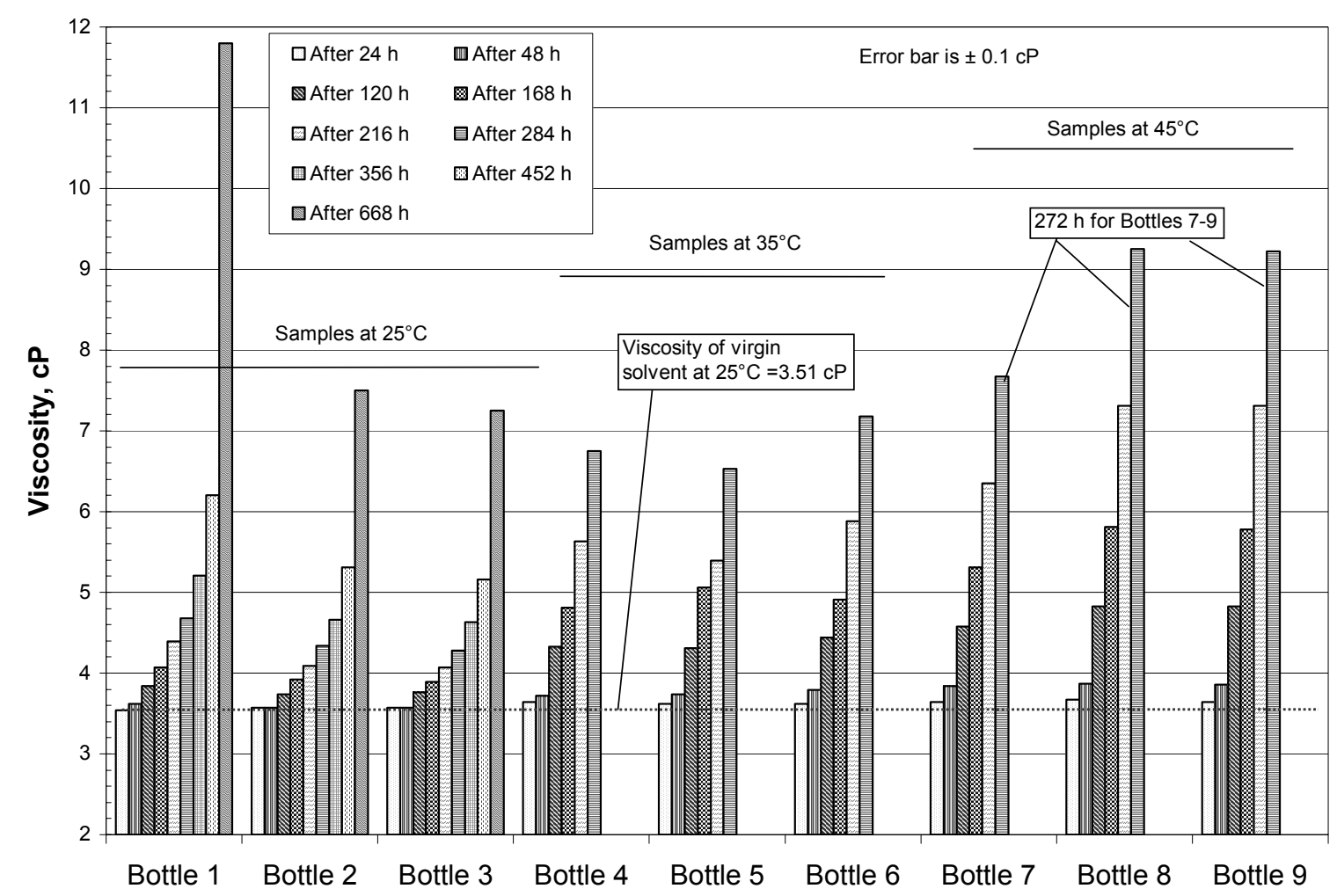

Fig. 4. Viscosity change for CSSX solvent from evaporation at three temperatures.

\subsubsection{Solvent Composition Changes Produced by Evaporation}

Evaporation produced changes in the composition of the solvent, as shown in Tables 3-5. The ratio of the calix to modifier did not vary greatly, generally less than $5 \%$, implying that the principal phenomenon was the disappearance of the diluent, Isopar ${ }^{\circledR}$ L. Within experimental error, the temperature maintained during evaporation did not affect the ratios of modifier-to-calix concentration as a function of time. Figures 6-8 show the correlations between the modifier concentration and the density of the solvent during evaporation at the three temperatures. For comparison purposes, density values as a function of modifier concentration are shown for solvents of various known compositions. In each of the figures, the HPLC data for all three bottles are compared with the data from the NMR determinations. The data obtained at $45^{\circ} \mathrm{C}$ using HPLC and NMR are in good agreement, as shown in Fig. 6. The data for $35^{\circ} \mathrm{C}$ in Fig. 7 show more scatter between bottles, while the data for $25^{\circ} \mathrm{C}$ in Fig. 8 have the most scatter between the values for the individual bottles. Figure 9 is a plot of the viscosity versus the 
modifier concentrations for the $25^{\circ} \mathrm{C}$ bottles; the trends indicated are consistent with loss of the relatively low-viscosity diluent.

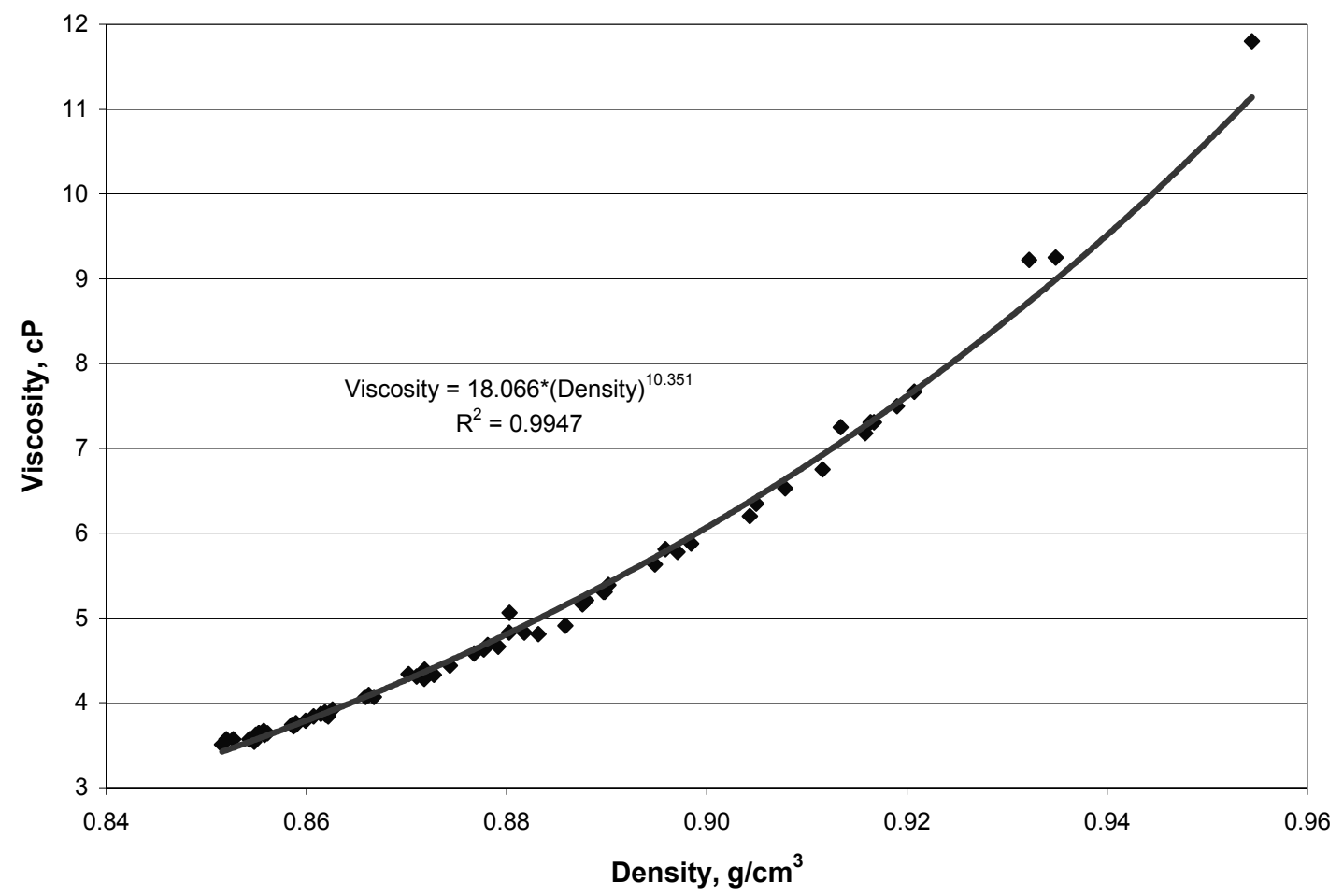

Fig. 5. Correlation of viscosity and density for CSSX solvent during evaporation.

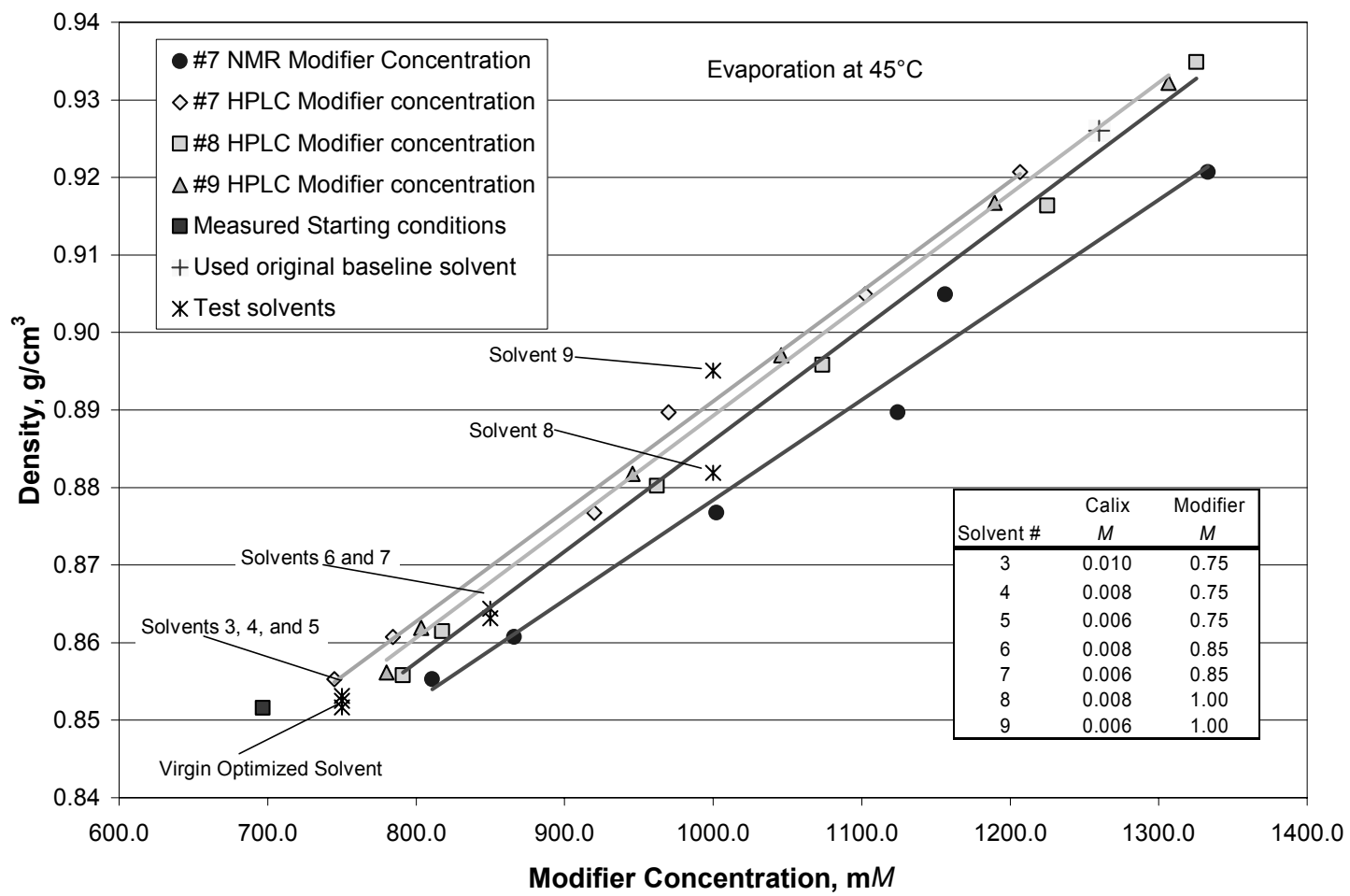

Fig. 6. Density of solvent versus the modifier concentration during evaporation at $45^{\circ} \mathrm{C}$. 
Table 3. Physical and chemical parameters of solvent evaporation at $25^{\circ} \mathrm{C}$

\begin{tabular}{|c|c|c|c|c|c|c|c|c|}
\hline $\begin{array}{l}\text { Time } \\
\text { (h) }\end{array}$ & $\begin{array}{l}\text { Density } \\
\left(\mathrm{g} / \mathrm{cm}^{3}\right. \\
\pm 0.05 \%)\end{array}$ & $\begin{array}{l}\text { Viscosity } \\
\quad(\mathrm{cP} \\
\pm 0.1 \mathrm{cP})\end{array}$ & $\begin{array}{c}\text { HPLC } \\
\text { Cs-7SB } \\
(\mathrm{m} M \\
\pm 10 \%)\end{array}$ & $\begin{array}{l}\text { HPLC } \\
\text { calix } \\
(\mathrm{m} M \\
\pm 10 \%)\end{array}$ & $\begin{array}{c}\text { HPLC } \\
\text { Ratio, } \\
\text { Cs-7SB/calix }\end{array}$ & $\begin{array}{c}\text { HPLC } \\
\text { diluent } \\
\text { lost }(\%)\end{array}$ & $\begin{array}{c}\text { NMR } \\
\text { diluent } \\
\text { lost }(\%)\end{array}$ & $\begin{array}{c}\text { NMR } \\
\text { Cs-7SB } \\
(\mathrm{m} M \\
\pm 10 \%)\end{array}$ \\
\hline \multicolumn{9}{|c|}{ Bottle 1} \\
\hline 0 & 0.8516 & 3.51 & 697 & 6.4 & 108.8 & & & \\
\hline 24 & 0.8548 & 3.54 & 777 & 7.1 & 108.8 & 13.3 & 13.8 & 841 \\
\hline 48 & 0.8558 & 3.62 & 750 & 6.9 & 108.6 & 9.1 & 11.3 & 823 \\
\hline 120 & 0.8622 & 3.84 & 802 & 7.4 & 109.0 & 16.8 & 20.1 & 890 \\
\hline 168 & 0.8667 & 4.07 & 838 & 7.8 & 107.9 & 21.6 & 24.2 & 924 \\
\hline 216 & 0.8718 & 4.39 & 889 & 8.1 & 109.2 & 27.7 & 30.1 & 980 \\
\hline 284 & 0.8781 & 4.68 & 915 & 8.4 & 108.5 & 30.5 & 31.8 & 997 \\
\hline 356 & 0.8880 & 5.21 & 983 & 9.0 & 109.5 & 37.3 & 39.8 & 1088 \\
\hline 452 & 0.9043 & 6.20 & 1090 & 9.9 & 109.7 & 46.2 & 54.2 & 1298 \\
\hline 668 & 0.9544 & 11.80 & 1339 & 12.7 & 105.8 & 61.5 & & \\
\hline \multicolumn{9}{|c|}{ Bottle 2} \\
\hline 0 & 0.8516 & 3.51 & 697 & 6.4 & 108.8 & & & \\
\hline 24 & 0.8527 & 3.57 & 718 & 6.7 & 107.8 & 3.8 & & \\
\hline 48 & 0.8545 & 3.57 & 723 & 6.8 & 107.1 & 4.6 & & \\
\hline 120 & 0.8589 & 3.74 & 756 & 7.0 & 108.1 & 10.0 & & \\
\hline 168 & 0.8626 & 3.92 & 822 & 7.6 & 108.8 & 19.5 & & \\
\hline 216 & 0.8662 & 4.09 & 829 & 7.6 & 109.0 & 20.5 & & \\
\hline 284 & 0.8662 & 4.34 & 827 & 7.6 & 108.7 & 20.2 & & \\
\hline 356 & 0.8792 & 4.66 & 877 & 8.0 & 109.2 & 26.3 & & \\
\hline 452 & 0.8898 & 5.31 & 941 & 8.6 & 109.2 & 33.3 & & \\
\hline 668 & 0.9190 & 7.50 & 1141 & 10.6 & 107.6 & 49.9 & & \\
\hline \multicolumn{9}{|c|}{ Bottle 3} \\
\hline 0 & 0.8516 & 3.51 & 697 & 6.4 & 108.8 & & & \\
\hline 24 & 0.8520 & 3.57 & 712 & 6.6 & 107.7 & 2.7 & & \\
\hline 48 & 0.8543 & 3.57 & 685 & 6.4 & 107.3 & -2.3 & & \\
\hline 120 & 0.8590 & 3.76 & 744 & 6.9 & 107.5 & 8.1 & & \\
\hline 168 & 0.8618 & 3.89 & 786 & 7.0 & 112.7 & 14.5 & & \\
\hline 216 & 0.8659 & 4.07 & 854 & 7.6 & 111.8 & 23.6 & & \\
\hline 284 & 0.8718 & 4.28 & 844 & 7.5 & 112.8 & 22.4 & & \\
\hline 356 & 0.8777 & 4.63 & 979 & 8.6 & 113.7 & 36.9 & & \\
\hline 452 & 0.8876 & 5.16 & 1091 & 9.6 & 113.2 & 46.3 & & \\
\hline 668 & 0.9134 & 7.25 & 1156 & 10.8 & 107.2 & 50.9 & & \\
\hline
\end{tabular}


Table 4. Physical and chemical parameters of solvent evaporation at $35^{\circ} \mathrm{C}$

\begin{tabular}{|c|c|c|c|c|c|c|c|c|}
\hline $\begin{array}{l}\text { Time } \\
\text { (h) }\end{array}$ & $\begin{array}{c}\text { Density } \\
\left(\mathrm{g} / \mathrm{cm}^{3}\right. \\
\pm 0.05 \%)\end{array}$ & $\begin{array}{c}\text { Viscosity } \\
\text { (cP } \\
\pm 0.1 \mathrm{cP})\end{array}$ & $\begin{array}{c}\text { HPLC } \\
\text { Cs-7SB } \\
(\mathrm{m} M \\
\pm 10 \%)\end{array}$ & $\begin{array}{l}\text { HPLC } \\
\text { Calix } \\
(\mathrm{m} M \\
\pm 10 \%)\end{array}$ & $\begin{array}{c}\text { HPLC } \\
\text { Ratio, } \\
\text { Cs-7SB/calix }\end{array}$ & $\begin{array}{c}\text { HPLC } \\
\text { diluent } \\
\text { lost (\%) }\end{array}$ & $\begin{array}{c}\text { NMR } \\
\text { diluent } \\
\text { lost }(\%)\end{array}$ & $\begin{array}{c}\text { NMR } \\
\text { Cs-7SB } \\
(\mathrm{m} M \\
\pm 10 \%)\end{array}$ \\
\hline \multicolumn{9}{|c|}{ Bottle 4} \\
\hline 0 & 0.8516 & 3.51 & 697 & 6.4 & 108.8 & & & \\
\hline 24 & 0.8559 & 3.64 & 773 & 7.1 & 108.8 & 12.6 & 8.3 & 802 \\
\hline 48 & 0.8587 & 3.72 & 782 & 7.2 & 108.5 & 14.0 & 22.2 & 907 \\
\hline 120 & 0.8727 & 4.33 & 883 & 8.1 & 109.2 & 27.1 & 28.7 & 966 \\
\hline 168 & 0.8832 & 4.81 & 931 & 8.5 & 110.0 & 32.3 & 37.0 & 1054 \\
\hline 216 & 0.8948 & 5.63 & 1020 & 9.2 & 11065 & 40.6 & 45.9 & 1168 \\
\hline 284 & 0.9116 & 6.75 & 1136 & 10.3 & 110.5 & 49.5 & 51.4 & 1251 \\
\hline \multicolumn{9}{|c|}{ Bottle 5} \\
\hline 0 & 0.8516 & 3.51 & 697 & 6.4 & 108.8 & & & \\
\hline 24 & 0.8552 & 3.62 & 785 & 7.0 & 111.5 & 14.4 & & \\
\hline 48 & 0.8586 & 3.74 & 765 & 6.9 & 111.0 & 14.4 & & \\
\hline 120 & 0.8710 & 4.31 & 865 & 7.7 & 112.8 & 24.9 & & \\
\hline 168 & 0.8803 & 5.06 & 1027 & 9.0 & 113.7 & 41.2 & & \\
\hline 216 & 0.8902 & 5.39 & 1029 & 9.0 & 114.0 & 41.4 & & \\
\hline 284 & 0.9078 & 6.53 & 1163 & 10.2 & 114.3 & 51.4 & & \\
\hline \multicolumn{9}{|c|}{ Bottle 6} \\
\hline 0 & 0.8516 & 3.51 & 697 & 6.4 & 108.8 & & & \\
\hline 24 & 0.8599 & 3.79 & 766 & 6.8 & 112.8 & 11.6 & & \\
\hline 48 & 0.8549 & 3.62 & 796 & 7.0 & 113.2 & 16.0 & & \\
\hline 120 & 0.8743 & 4.44 & 891 & 7.9 & 112.4 & 27.9 & & \\
\hline 168 & 0.8859 & 4.91 & 986 & 8.8 & 112.5 & 37.6 & & \\
\hline 216 & 0.8984 & 5.88 & 1183 & 10.5 & 112.8 & 52.7 & & \\
\hline 284 & 0.9158 & 7.18 & 1216 & 10.7 & 113.7 & 54.8 & & \\
\hline
\end{tabular}


Table 5. Physical and chemical parameters of solvent evaporation at $45^{\circ} \mathrm{C}$

\begin{tabular}{|c|c|c|c|c|c|c|c|c|}
\hline $\begin{array}{l}\text { Time } \\
\text { (h) }\end{array}$ & $\begin{array}{l}\text { Density } \\
\left(\mathrm{g} / \mathrm{cm}^{3}\right. \\
\pm 0.05 \%)\end{array}$ & $\begin{array}{l}\text { Viscosity } \\
\quad(\mathrm{cP} \\
\pm 0.1 \mathrm{cP})\end{array}$ & $\begin{array}{c}\text { HPLC } \\
\text { Cs-7SB } \\
(\mathrm{m} M \\
\pm 10 \%)\end{array}$ & $\begin{array}{l}\text { HPLC } \\
\text { Calix } \\
(\mathrm{m} M \\
\pm 10 \%)\end{array}$ & $\begin{array}{c}\text { HPLC } \\
\text { Ratio, } \\
\text { Cs-7SB/calix }\end{array}$ & $\begin{array}{c}\text { HPLC } \\
\text { diluent } \\
\text { lost (\%) }\end{array}$ & $\begin{array}{c}\text { NMR } \\
\text { diluent } \\
\text { lost }(\%)\end{array}$ & $\begin{array}{c}\text { NMR } \\
\text { Cs- 7SB } \\
(\mathrm{m} M \\
\pm 10 \%)\end{array}$ \\
\hline \multicolumn{9}{|c|}{ Bottle 7} \\
\hline 0 & 0.8516 & 3.51 & 697 & 6.4 & 108.8 & & & \\
\hline 24 & 0.8553 & 3.64 & 745 & 6.8 & 109.0 & 8.3 & 9.6 & 811 \\
\hline 48 & 0.8607 & 3.84 & 784 & 7.2 & 109.7 & 14.3 & 17.2 & 866 \\
\hline 120 & 0.8767 & 4.58 & 920 & 8.4 & 110.1 & 31.1 & 32.3 & 1002 \\
\hline 168 & 0.8897 & 5.31 & 970 & 8.7 & 111.3 & 36.1 & 42.7 & 1124 \\
\hline 216 & 0.9049 & 6.35 & 1102 & 9.8 & 112.0 & 47.2 & 45.1 & 1156 \\
\hline 272 & 0.9207 & 7.67 & 1207 & 10.8 & 111.9 & 54.2 & 56.0 & 1333 \\
\hline \multicolumn{9}{|c|}{ Bottle 8} \\
\hline 0 & 0.8516 & 3.51 & 697 & 6.4 & 108.8 & & & \\
\hline 24 & 0.8558 & 3.67 & 7917 & 7.2 & 110.2 & 15.3 & & \\
\hline 48 & 0.8615 & 3.87 & 818 & 7.4 & 110.8 & 19.0 & & \\
\hline 120 & 0.8802 & 4.83 & 962 & 8.6 & 111.4 & 35.4 & & \\
\hline 168 & 0.8958 & 5.81 & 1074 & 9.6 & 112.2 & 45.0 & & \\
\hline 216 & 0.9164 & 7.31 & 1225 & 10.8 & 112.7 & 55.3 & & \\
\hline 272 & 0.9348 & 9.25 & 1326 & 11.8 & 112.7 & 60.8 & & \\
\hline \multicolumn{9}{|c|}{ Bottle 9} \\
\hline 0 & 0.8516 & 3.51 & 697 & 6.4 & 108.8 & & & \\
\hline 24 & 0.8561 & 3.64 & 780 & 7.0 & 110.8 & 13.7 & & \\
\hline 48 & 0.8619 & 3.86 & 803 & 7.2 & 111.5 & 17.0 & & \\
\hline 120 & 0.8818 & 4.83 & 946 & 8.4 & 112.0 & 33.8 & & \\
\hline 168 & 0.8970 & 5.78 & 1046 & 9.4 & 111.9 & 42.8 & & \\
\hline 216 & 0.9167 & 7.31 & 1189 & 10.6 & 111.8 & 53.1 & & \\
\hline 272 & 0.9322 & 9.22 & 1307 & 11.6 & 112.8 & 59.8 & & \\
\hline
\end{tabular}




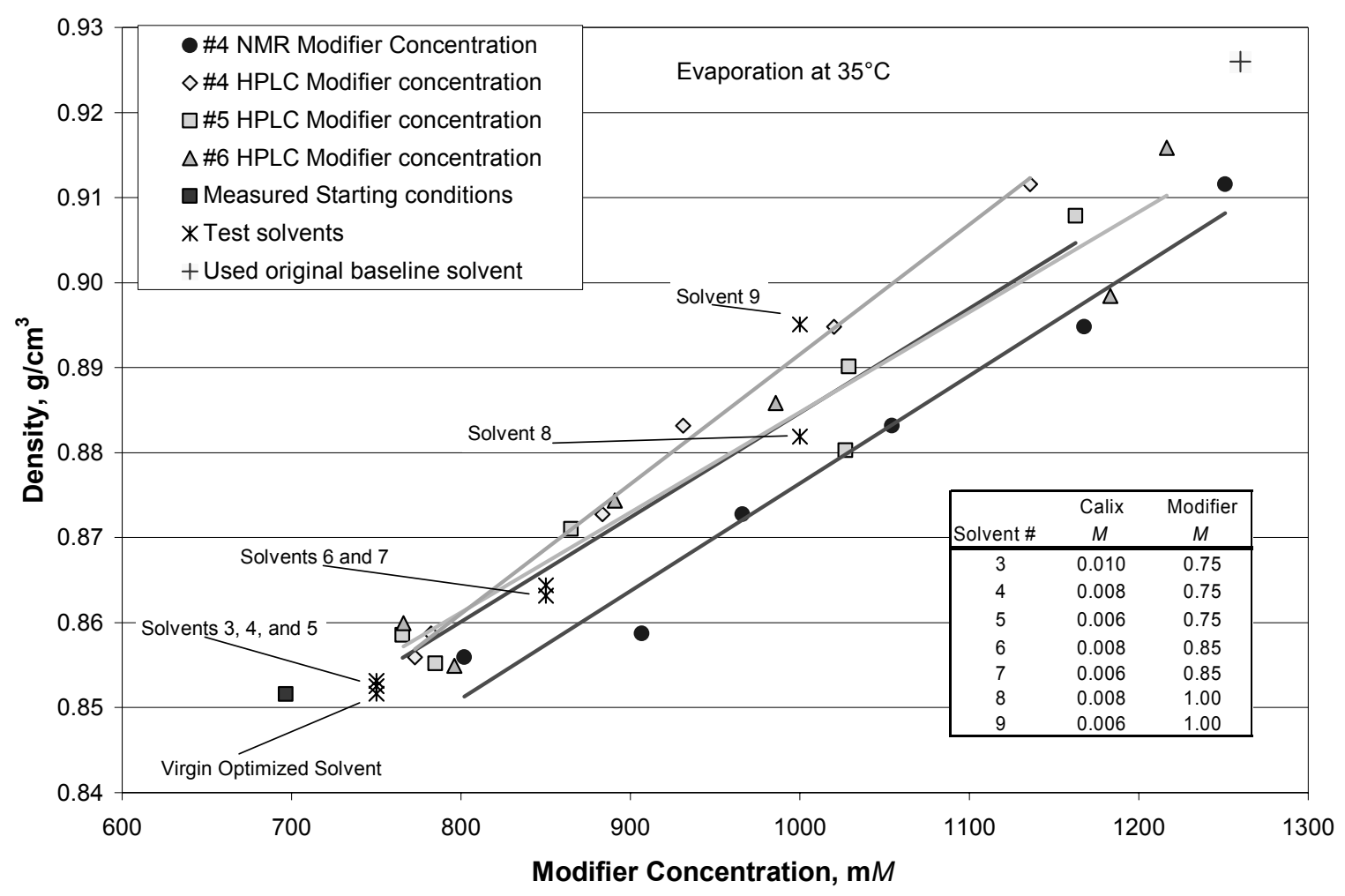

Fig. 7. Density of solvent versus the modifier concentration during evaporation at $35^{\circ} \mathrm{C}$.

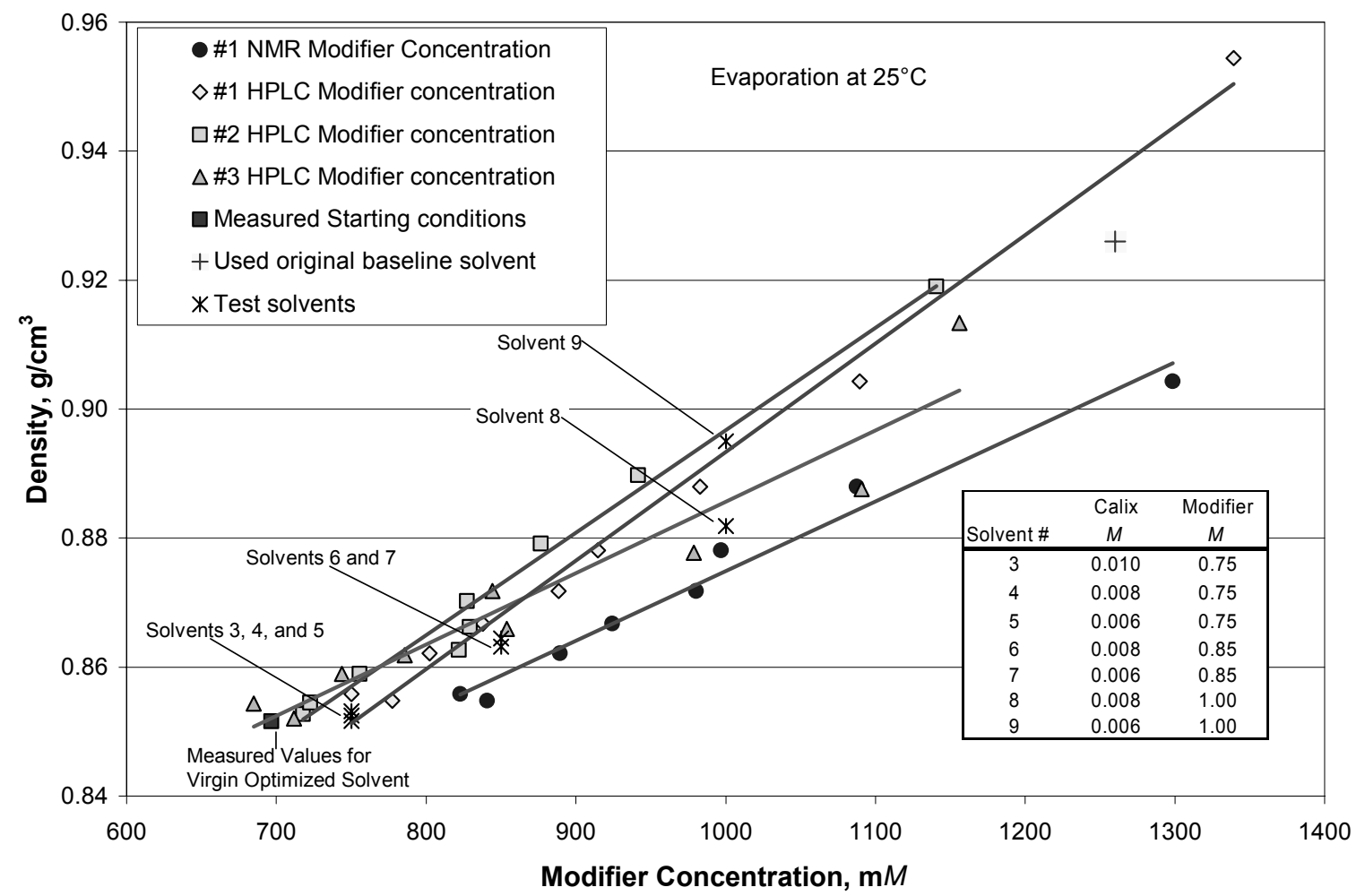

Fig. 8. Density of solvent versus the modifier concentration during evaporation at $25^{\circ} \mathrm{C}$. 


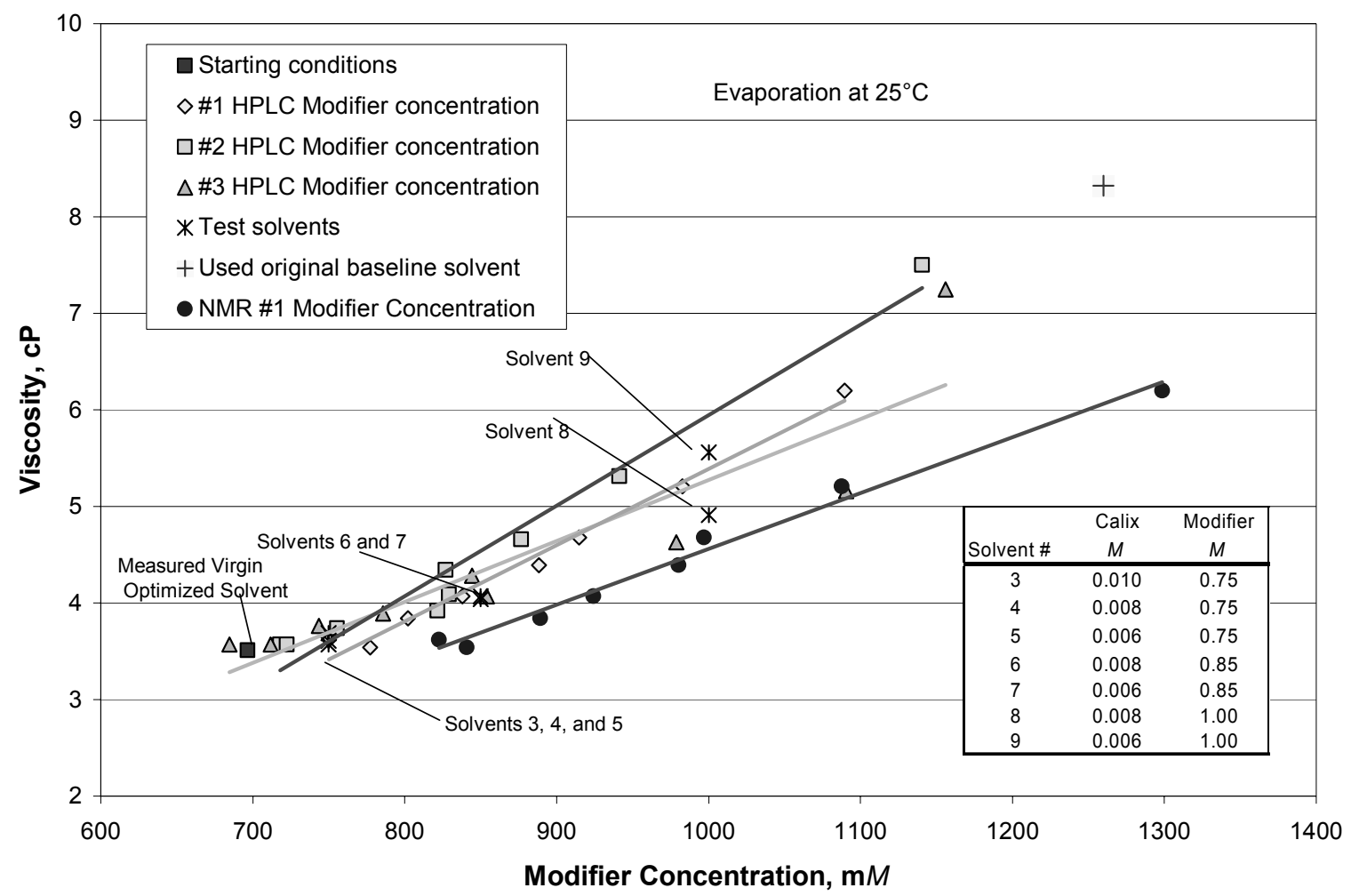

Fig. 9. Viscosity of solvent versus the modifier concentration during evaporation at $25^{\circ} \mathrm{C}$.

Figure 10 shows a plot of the Isopar ${ }^{\circledR} \mathrm{L}$ lost versus the density for all samples and bottles and indicates how much of the diluent must be added back to the solvent after the density is measured. Figure 10 also shows (via a dotted line) the calculated amount of Isopar ${ }^{\circledR}$ L lost based on the density of the solvent (assuming that only the diluent is lost). This figure illustrates that a density measurement correlation can be a good measure of diluent loss. Even in the first $10 \%$ of the diluent loss, the density change is enough to serve as an indicator of diluent loss. Figure 11 shows the same type of data for the Isopar ${ }^{\mathbb{B}} \mathrm{L}$ loss versus the measured viscosities. The change in viscosity during the initial loss of Isopar ${ }^{\circledR} \mathrm{L}$ is not a reliable indicator of diluent loss.

Additional calculations were made to compare the amount of diluent loss calculated from the amount of Cs-7SB determined by HPLC with that calculated from the density at each measurement sampling point. The calculation model, used by Argonne National Laboratory $(\mathrm{ANL})^{1,3}$, assumes that no component interaction occurs in the solvent. The following values are assumed for a temperature of $25^{\circ} \mathrm{C}$ :

- Calix molecular weight is $1149.53 \mathrm{~g} / \mathrm{mol}$ and density is $1.054 \mathrm{~g} / \mathrm{cm}^{3}$

- Cs-7SB molecular weight is $338.35 \mathrm{~g} / \mathrm{mol}$ and density is $1.1735 \mathrm{~g} / \mathrm{cm}^{3}$

- TOA molecular weight is $353.69 \mathrm{~g} / \mathrm{mol}$ and density is $0.809 \mathrm{~g} / \mathrm{cm}^{3}$

- Isopar $^{\circledR} \mathrm{L}$ density is $0.7597 \mathrm{~g} / \mathrm{cm}^{3}$.

The calculations of the density at each sample period assumed that all the mass lost during each evaporation time could be attributed only to the Isopar ${ }^{\circledR} \mathrm{L}$, that the mass lost during sampling was the composition calculated after the loss of diluent during that period for that sample (including calix, diluent, modifier, and TOA), and that the starting composition contained the prepared composition of calix and modifier. Figures 12-14 show the results of the calculations 
compared with those of the HPLC analysis for the three experimental temperatures. The good agreement indicates that to a reasonable certainty, the loss of only Isopar ${ }^{\circledR}$ L during evaporation is a reasonable assumption.

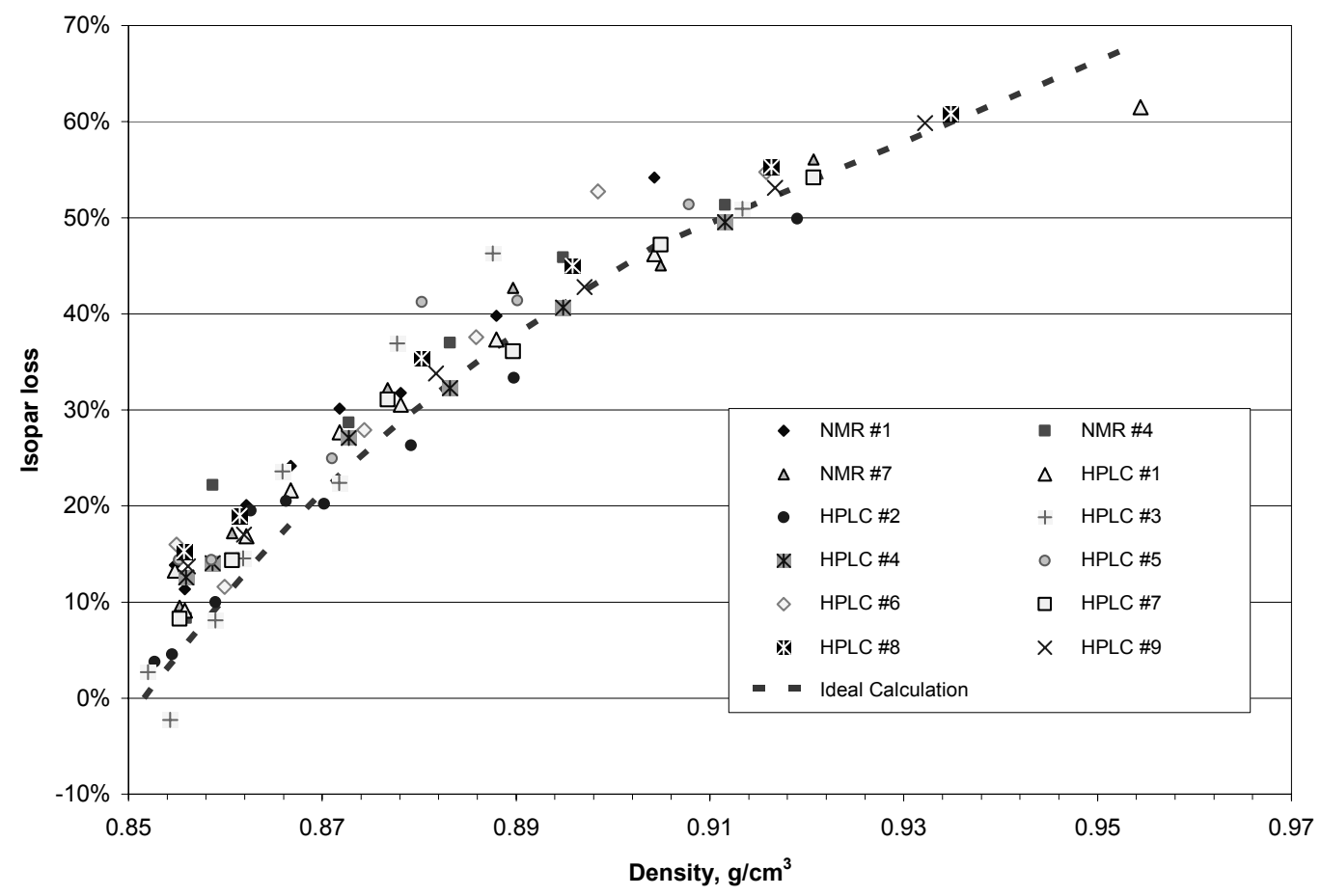

Fig. 10. Solvent density versus the HPLC-and NMR-measured diluent loss.

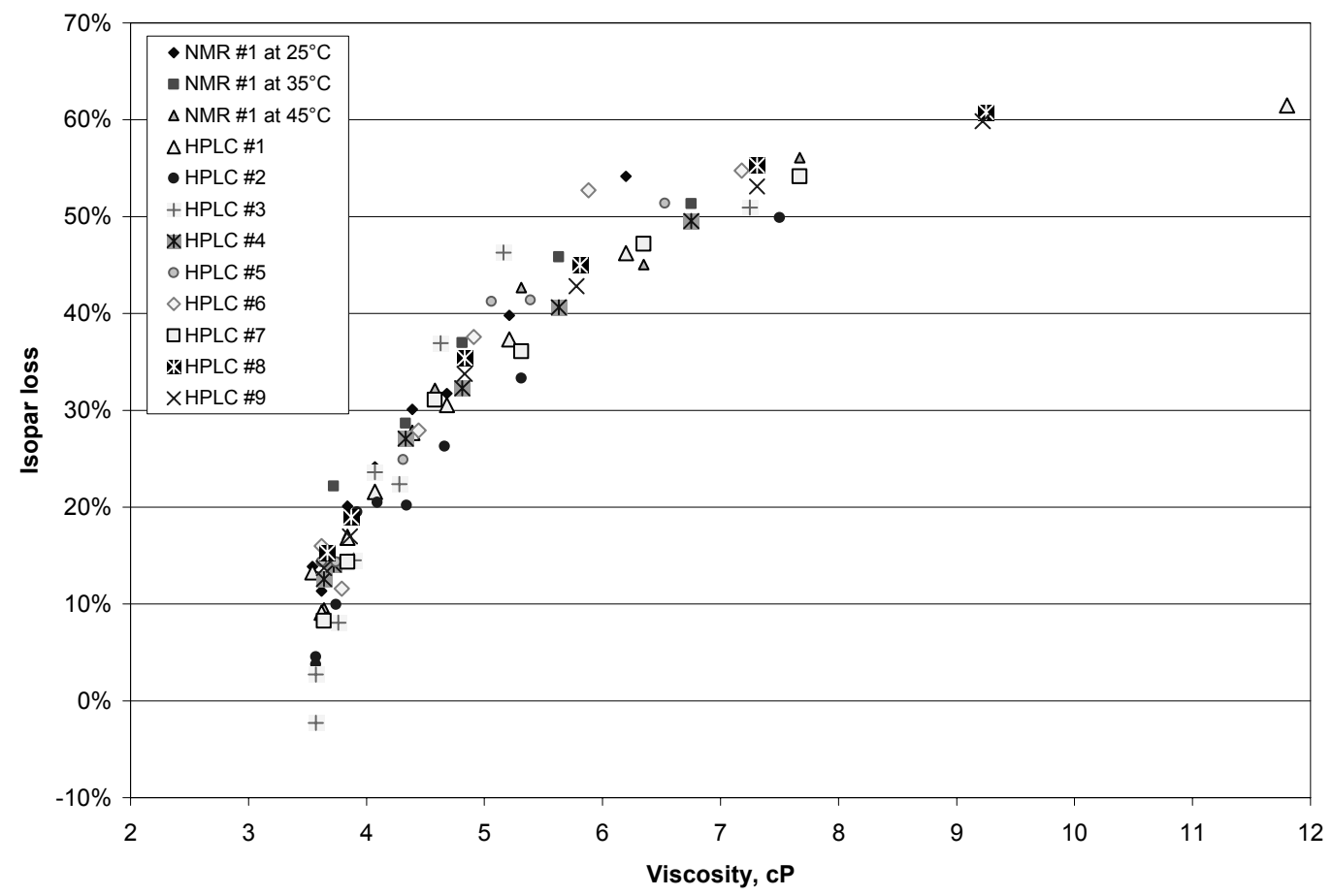

Fig. 11. Solvent viscosity versus the HPLC- and NMR-measured diluent loss. 


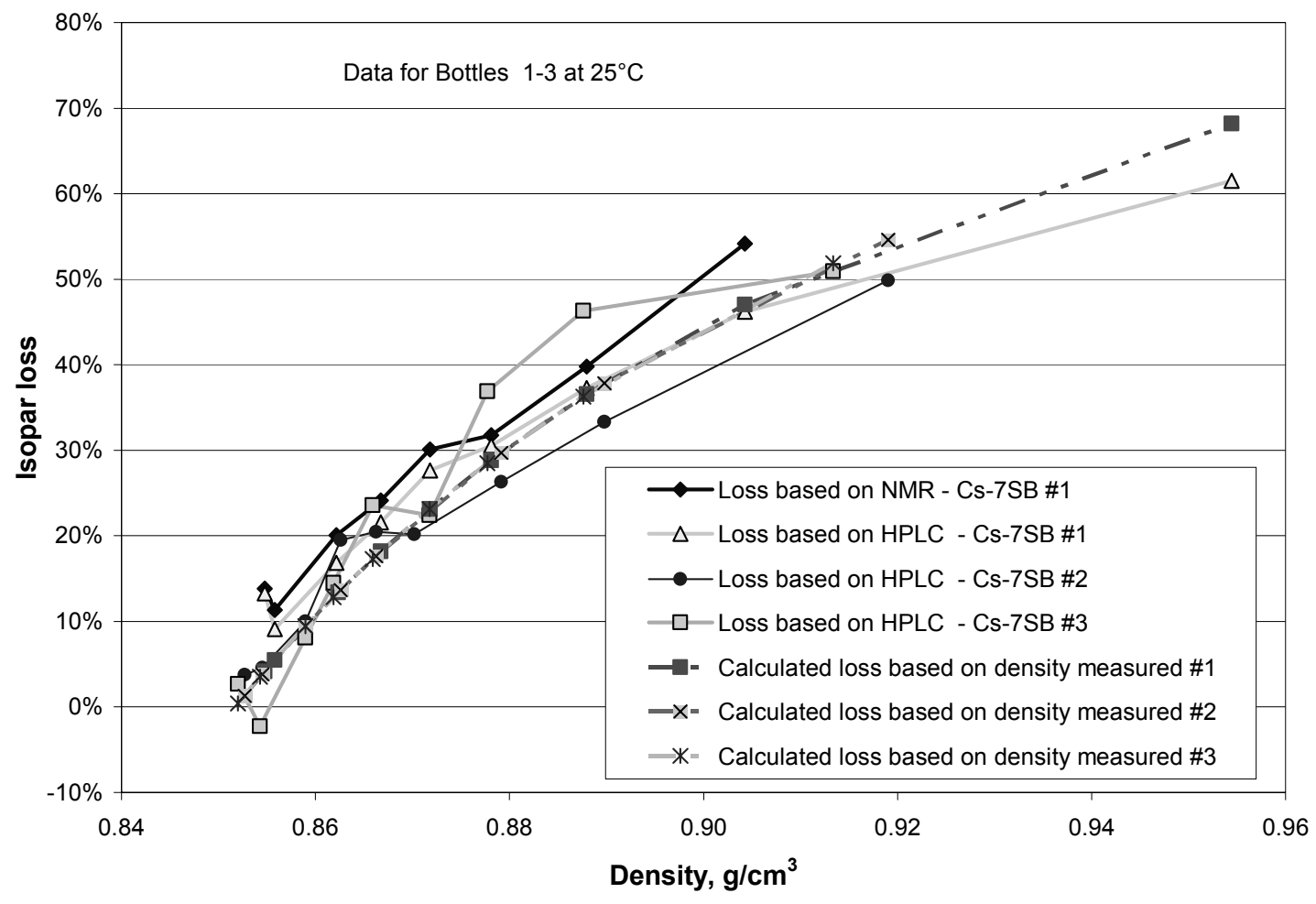

Fig. 12. Solvent density versus the measured and calculated diluent loss at $25^{\circ} \mathrm{C}$.

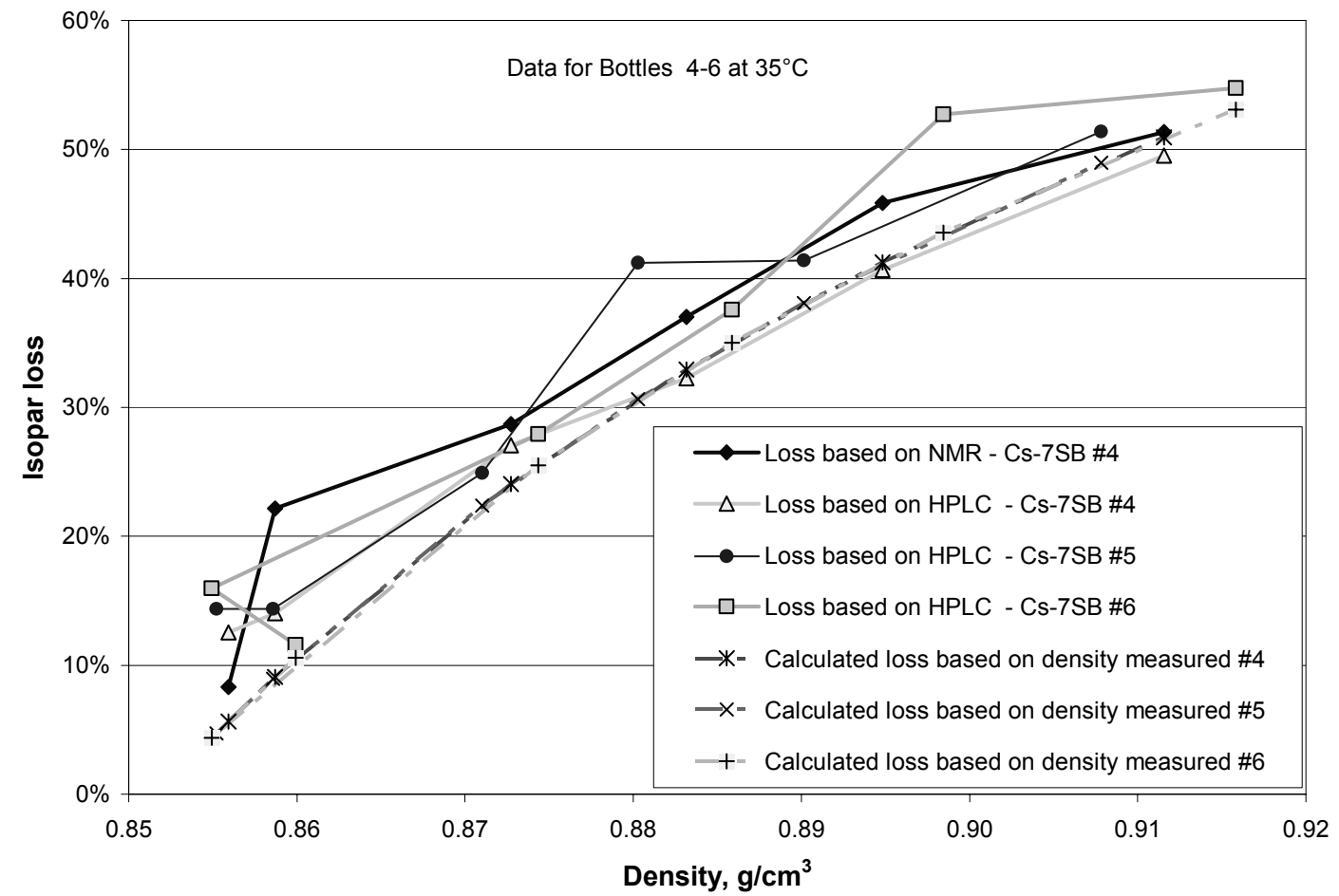

Fig. 13. Solvent density versus the measured and calculated diluent loss at $35^{\circ} \mathrm{C}$. 


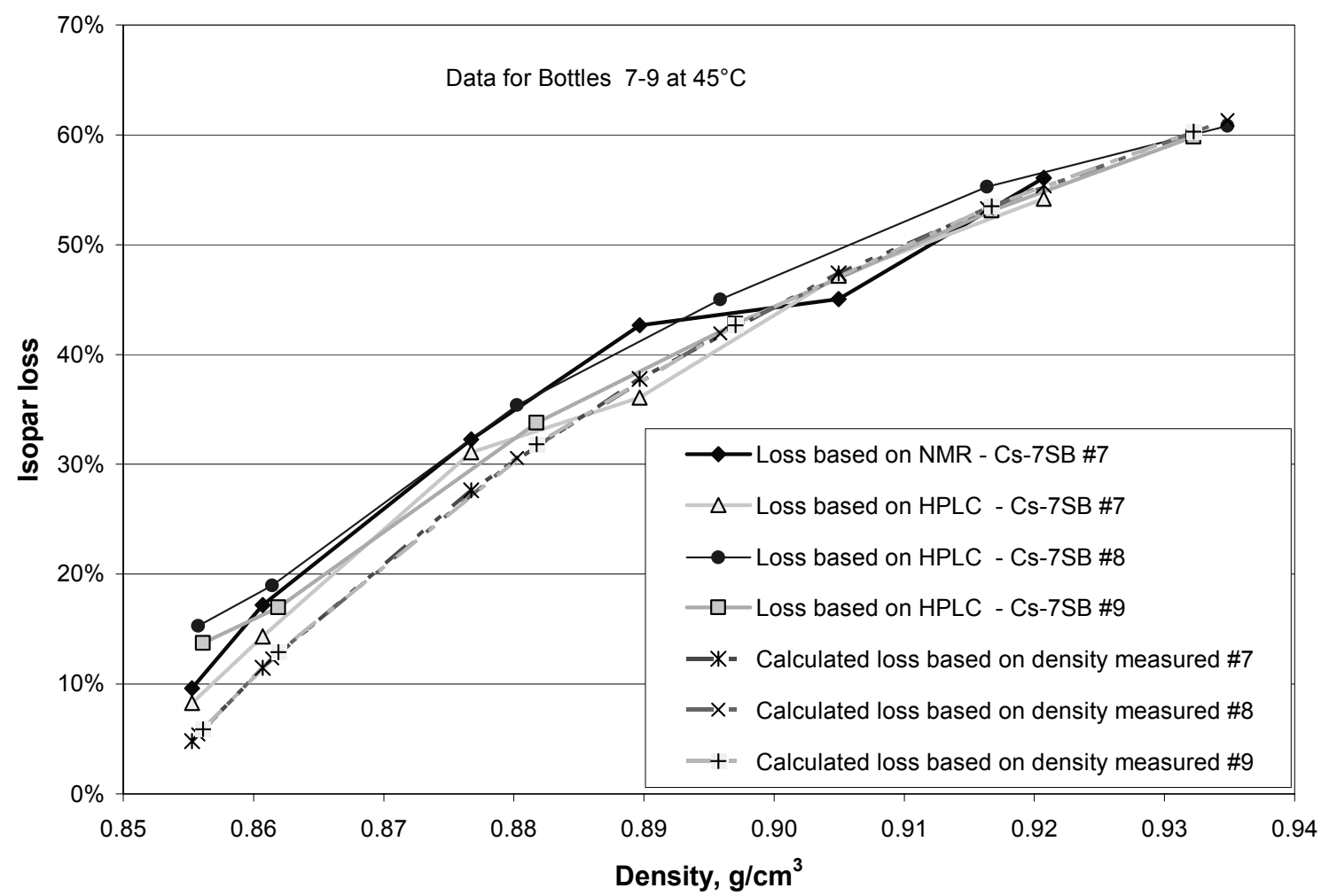

Fig. 14. Solvent density versus the measured and calculated diluent loss at $45^{\circ} \mathrm{C}$.

\subsection{SOLVENT CHEMICAL INTERACTIONS}

Solvent was contacted with simulant (with scrub solution, mixed in proportions corresponding to the flow rates in the extraction section of the CSSX flowsheet), strip solution, and wash solution in a water bath controlled at about $25^{\circ} \mathrm{C}$ and agitated at 140 oscillations per minute. Samples of each solvent were removed for density and viscosity measurements and small samples were taken and submitted for HPLC analysis. As Fig. 15-16 and Tables 6-8 show, continuous contact of solvent with simulant, strip solution, and wash solution caused no apparent changes in either density or viscosity during the period of contact. The variation in sample density in flasks 1,2 , and 3 results from the use of 1- and 2-mL pycnometers which have a larger error bar than the 50 -mL volumetric flasks $( \pm 0.004$ vs \pm 0.0004$)$ used for the other samples. The reason that the first sample from flask 1 had a high density was that it was probably contaminated with the aqueous matrix. Overall results from the density measurements give no reason for considering that chemical interaction affects the solvent density.

Similarly, little change was seen in the viscosity of the solvent over the course of contacts with simulant, strip solution, or wash solution. A slight increase in the measured viscosity over that of the virgin solvent was seen in the initial samples, but very little change was seen in subsequent samples. Because of the small volume of solvent in these flasks, viscosities for the solvents from flasks 1,2 , and 3 were not measured initially, but were measured at the end of the tests. No viscosity measurements gave any indication that chemical interactions had an effect on solvent viscosity. 


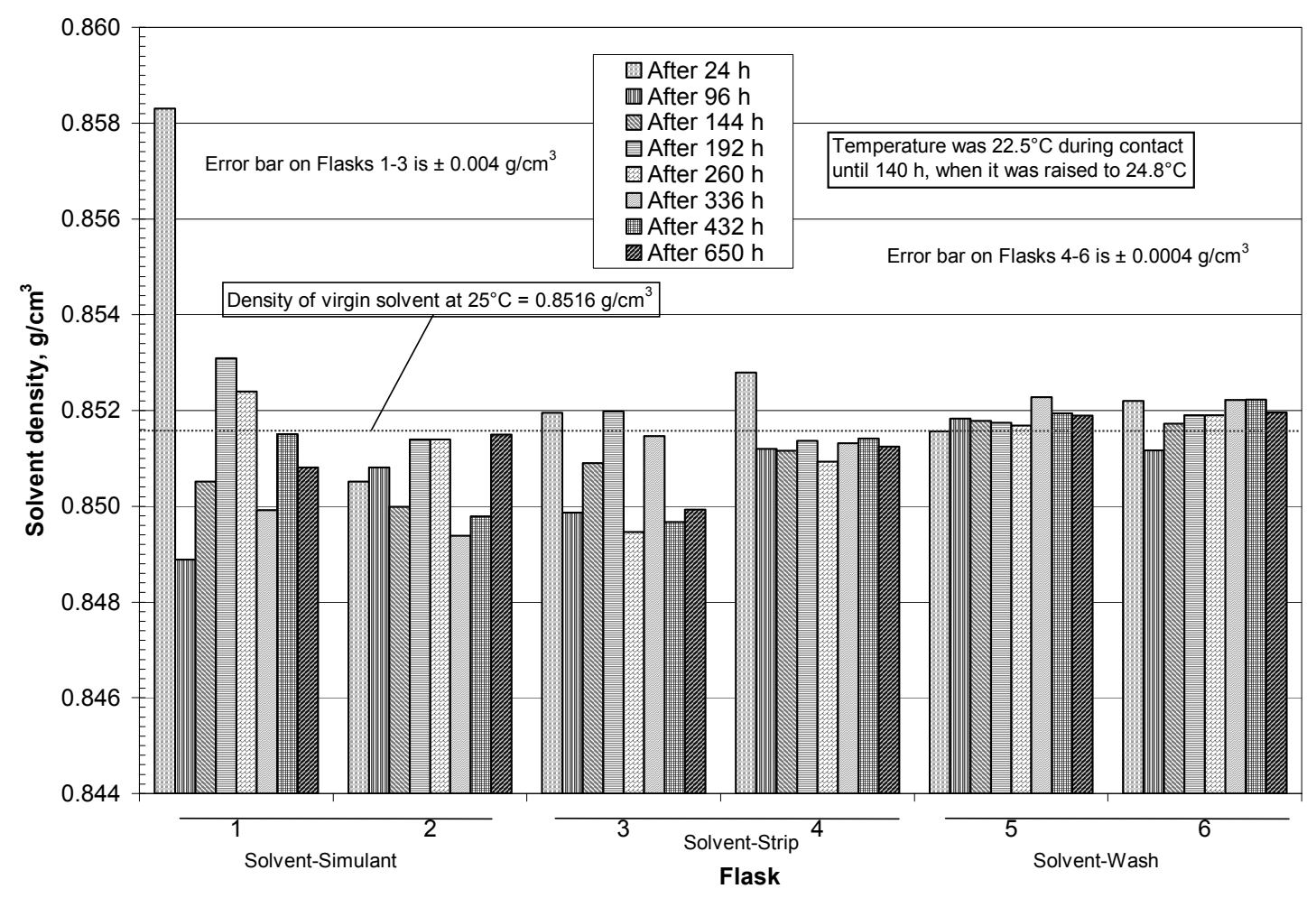

Fig. 15. Density of CSSX solvent after contact with simulant, strip, and wash solutions.

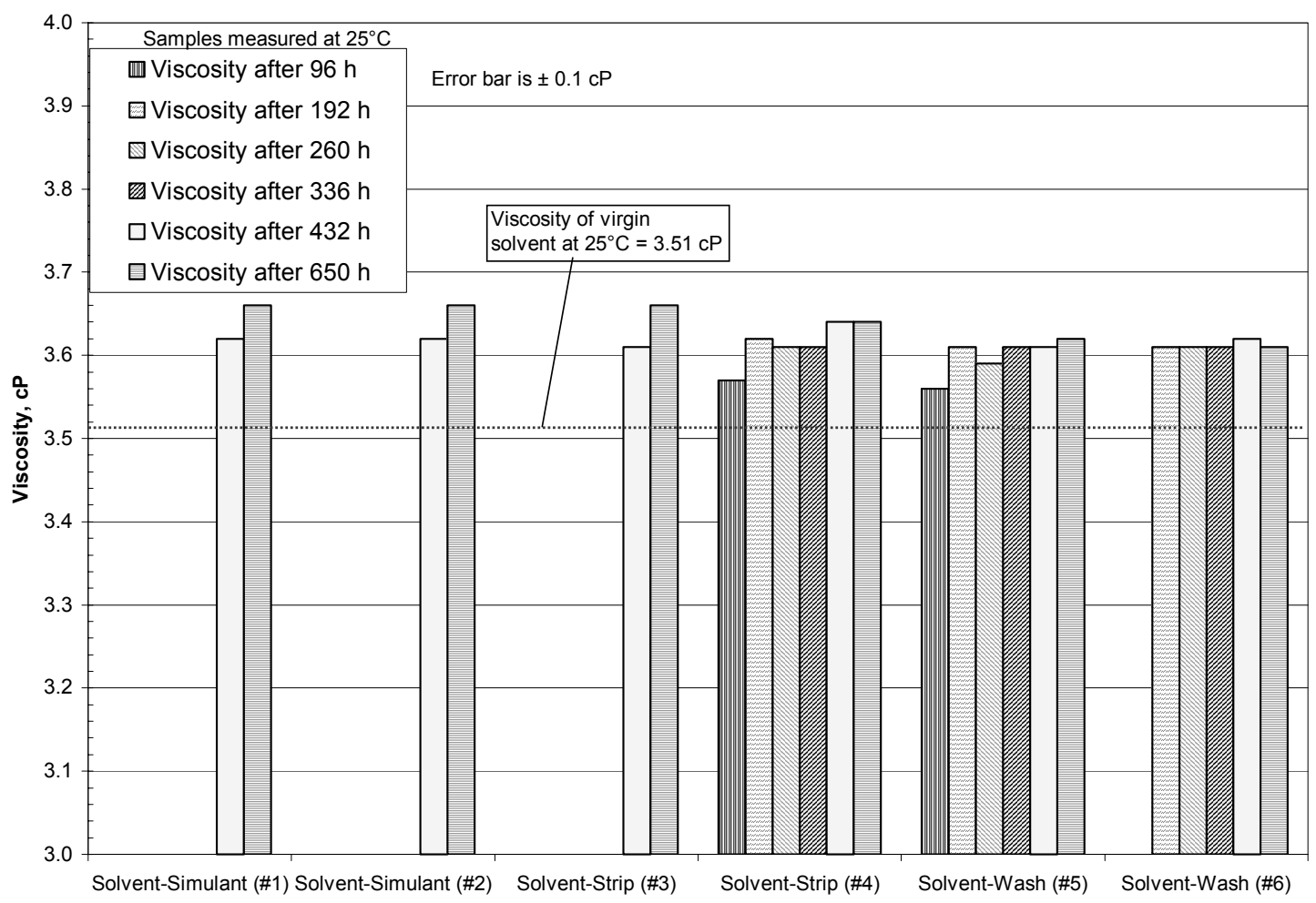

Fig. 16. Viscosity of CSSX solvent after contact with strip and wash solutions. 
Table 6. Chemical Interaction Test-solvent and simulant

\begin{tabular}{rcccccc}
\hline $\begin{array}{c}\text { Time } \\
(\mathrm{h})\end{array}$ & $\begin{array}{c}\text { Density } \\
\left(\mathrm{g} / \mathrm{cm}^{3}\right)\end{array}$ & $\begin{array}{c}\text { Viscosity } \\
(\mathrm{cP})\end{array}$ & $\begin{array}{c}\text { HPLC } \\
\text { Cs-7SB } \\
(\mathrm{m} M)\end{array}$ & $\begin{array}{c}\text { HPLC } \\
\text { calix } \\
(\mathrm{m} M)\end{array}$ & $\begin{array}{c}\text { HPLC } \\
\text { ratio, } \\
\text { Cs-7SB/calix }\end{array}$ & $\begin{array}{c}\text { HPLC } \\
\text { diluent } \\
\text { lost }(\%)\end{array}$ \\
\hline 0 & 0.8516 & 3.51 & 697 & 6.4 & 108.8 & \\
24 & 0.8583 & & 737 & 6.7 & 109.4 & 7.0 \\
96 & 0.8489 & & 724 & 6.6 & 110.1 & 4.8 \\
144 & 0.8505 & & 693 & 6.4 & 108.5 & -0.8 \\
192 & 0.8531 & & 694 & 6.4 & 108.2 & -0.6 \\
260 & 0.8524 & & 676 & 6.2 & 108.8 & -3.9 \\
336 & 0.8499 & & 675 & 6.3 & 107.9 & -4.1 \\
432 & 0.8515 & 3.62 & 667 & 6.1 & 109.3 & -5.8 \\
650 & 0.8508 & 3.66 & 667 & 6.2 & 108.1 & -5.6 \\
& & & Bottle 2 & & & \\
0 & 0.8516 & 3.51 & 697 & 6.4 & 108.8 & 6.8 \\
24 & 0.8505 & & 736 & 6.7 & 110.1 & -7.4 \\
96 & 0.8508 & & 659 & 6.1 & 107.7 & -8.7 \\
144 & 0.8500 & & 652 & 6.1 & 107.6 & -7.0 \\
192 & 0.8514 & & 661 & 6.1 & 108.4 & -7.6 \\
260 & 0.8514 & & 658 & 6.1 & 108.7 & -6.2 \\
336 & 0.8494 & & 664 & 6.0 & 111.6 & 111.9 \\
432 & 0.8498 & 3.62 & 671 & 6.0 & 114.4 & -3.2 \\
650 & 0.8515 & 3.66 & 680 & 5.9 & & \\
\hline
\end{tabular}

The results of the HPLC analysis of all the solvent samples submitted show that virtually no changes took place in either the modifier or calix concentrations during the course of the test. The analytical results are shown in Figs. 17-19 and Tables 9-11. Figure 17 shows the modifier concentration in the solvent in each flask for all of the samples during the test. The HPLC error bar is $\pm 10 \%$, and all of the values obtained (both larger and smaller) differ from the starting concentration by less than that value. The calculated value for the modifier concentration was $750 \mathrm{~m} M$, based on the quantity of modifier added to the solvent when it was formulated. The values obtained from the HPLC averaged about 7\% lower for the sample of virgin solvent submitted. The calix concentrations in Fig. 18 are also distributed about the $6.4 \mathrm{~m} M$ value obtained during the measurement for the virgin solvent. (The HPLC error bar is $\pm 10 \%$.) The calculated concentration of the calix in the virgin solvent is $7 \mathrm{mM}$, about $8.6 \%$ more than the measured value. Part of the reason for the lower measured values is the pipetting technique during dilution of the samples for the HPLC analysis. All of the solvent samples were drawn into the pipette and then directly added to the dilution tube. During the latter stages of testing, it was observed that a small amount of the solvent would remain in the pipette tip and not be delivered to the dilution tube. The technique was not changed during the rest of the sampling, however, to ensure that all samples would be analyzed under the same conditions. Because the 
values of the modifier concentration remained basically the same during the tests, the concentration of the Isopar ${ }^{\circledR} \mathrm{L}$ did not change either.

Table 7. Chemical Interaction Test-solvent and strip solution

\begin{tabular}{rcccccc}
\hline $\begin{array}{c}\text { Time } \\
(\mathrm{h})\end{array}$ & $\begin{array}{c}\text { Density } \\
\left(\mathrm{g} / \mathrm{cm}^{3}\right)\end{array}$ & $\begin{array}{c}\text { Viscosity } \\
(\mathrm{cP})\end{array}$ & $\begin{array}{c}\text { HPLC } \\
\text { Cs-7SB } \\
(\mathrm{m} M)\end{array}$ & $\begin{array}{c}\text { HPLC } \\
\text { calix } \\
(\mathrm{m} M)\end{array}$ & $\begin{array}{c}\text { HPLC } \\
\text { ratio, } \\
\text { Cs-7SB/calix }\end{array}$ & $\begin{array}{c}\text { HPLC } \\
\text { diluent } \\
\text { lost }(\%)\end{array}$ \\
\hline 0 & 0.8516 & 3.51 & 697 & 6.4 & 108.8 & \\
24 & 0.8519 & & 734 & 6.7 & 110.0 & 6.5 \\
96 & 0.8499 & & 700 & 6.5 & 107.6 & 0.5 \\
144 & 0.8509 & & 685 & 6.4 & 107.9 & -2.2 \\
192 & 0.8520 & & 683 & 6.3 & 108.4 & -2.6 \\
260 & 0.8495 & & 681 & 6.2 & 109.2 & -2.9 \\
336 & 0.8515 & & 690 & 6.4 & 108.3 & -1.3 \\
432 & 0.8497 & 3.61 & 690 & 6.4 & 108.8 & -1.3 \\
650 & 0.8499 & 3.66 & 696 & 6.5 & 107.8 & -0.1 \\
& & & Bottle 4 & & & \\
0 & 0.8516 & 3.51 & 697 & 6.4 & 108.8 & 9.4 \\
24 & 0.8528 & & 752 & 6.9 & 109.2 & -5.2 \\
96 & 0.8512 & 3.57 & 669 & 6.1 & 109.0 & 1.8 \\
144 & 0.8512 & & 707 & 6.5 & 108.2 & 2.8 \\
192 & 0.8514 & 3.62 & 712 & 6.6 & 108.3 & 1.7 \\
260 & 0.8509 & 3.61 & 706 & 6.5 & 108.1 & 1.0 \\
336 & 0.8513 & 3.61 & 702 & 6.5 & 108.3 & -0.7 \\
432 & 0.8514 & 3.64 & 693 & 6.4 & 108.0 & 0.6 \\
650 & 0.8512 & 3.64 & 700 & 6.5 & 108.3 & \\
\hline
\end{tabular}

Figure 19 shows the ratio of the modifier to the calix for the test samples. This ratio shows whether one of the components is being preferentially removed from the solvent. Because the ratio was relatively constant and varied about the original value for the virgin solvent measurements, it can be assumed that minimal chemical interaction occurred between the solvent and the simulant, the solvent and the strip solution, and the solvent and the wash solution. The amount of the diluent Isopar $^{\circledR} \mathrm{L}$ added can be calculated from the concentration of modifier measured in the solvent. The calculated amount is subtracted from the amount in the virgin solvent and then divided by the amount in the virgin solvent. This gives the percent loss (if positive) or the percent gain (if negative). The results of these calculations are shown in Fig. 20. In all of the samples, the percent diluent gain or loss is within a few percentage points of zero. Finally, Fig. 21 shows a plot of the measured density versus the measured Cs-7SB concentration for each sample. Again, the values show no definite pattern but fluctuate around the conditions for the virgin solvent. This provides more evidence that chemical interactions under CSSX extraction, stripping, and solvent washing conditions do not cause an increase in solvent density. 
Table 8. Chemical Interaction Test-solvent and wash solution

\begin{tabular}{rcccccc}
\hline $\begin{array}{c}\text { Time } \\
(\mathrm{h})\end{array}$ & $\begin{array}{c}\text { Density } \\
\left(\mathrm{g} / \mathrm{cm}^{3}\right)\end{array}$ & $\begin{array}{c}\text { Viscosity } \\
(\mathrm{cP})\end{array}$ & $\begin{array}{c}\text { HPLC } \\
\text { Cs-7SB } \\
(\mathrm{m} M)\end{array}$ & $\begin{array}{c}\text { HPLC } \\
\text { calix } \\
(\mathrm{m} M)\end{array}$ & $\begin{array}{c}\text { HPLC } \\
\text { ratio, } \\
\text { Cs-7SB/calix }\end{array}$ & $\begin{array}{c}\text { HPLC } \\
\text { diluent } \\
\text { lost }(\%)\end{array}$ \\
\hline 0 & 0.8516 & 3.51 & 697 & 6.4 & 108.8 & \\
24 & 0.8516 & & 738 & 6.7 & 109.5 & 7.2 \\
96 & 0.8518 & 3.56 & 707 & 6.5 & 109.0 & 1.8 \\
144 & 0.8518 & & 712 & 6.5 & 109.3 & 2.8 \\
192 & 0.8517 & 3.61 & 715 & 6.5 & 109.3 & 3.2 \\
260 & 0.8517 & 3.59 & 715 & 6.5 & 109.4 & 3.3 \\
336 & 0.8523 & 3.61 & 712 & 6.5 & 109.3 & 2.8 \\
432 & 0.8519 & 3.61 & 713 & 6.5 & 109.7 & 3.0 \\
650 & 0.8519 & 3.62 & 723 & 6.6 & 109.4 & 4.7 \\
& & & Bottle 6 & & & \\
0 & 0.8516 & 3.51 & 697 & 6.4 & 108.8 & 10.1 \\
24 & 0.8522 & & 756 & 6.9 & 110.0 & 3.4 \\
96 & 0.8512 & & 716 & 6.5 & 109.5 & 5.0 \\
144 & 0.8517 & & 725 & 6.6 & 109.9 & 3.9 \\
192 & 0.8519 & 3.61 & 719 & 6.5 & 109.9 & 4.5 \\
260 & 0.8519 & 3.61 & 722 & 6.6 & 108.6 & 3.3 \\
336 & 0.8522 & 3.61 & 722 & 6.6 & 109.8 & 110.0 \\
432 & 0.8522 & 3.62 & 715 & 6.5 & 110.0 & \\
650 & 0.8520 & 3.61 & 713 & 6.5 & & \\
\hline
\end{tabular}




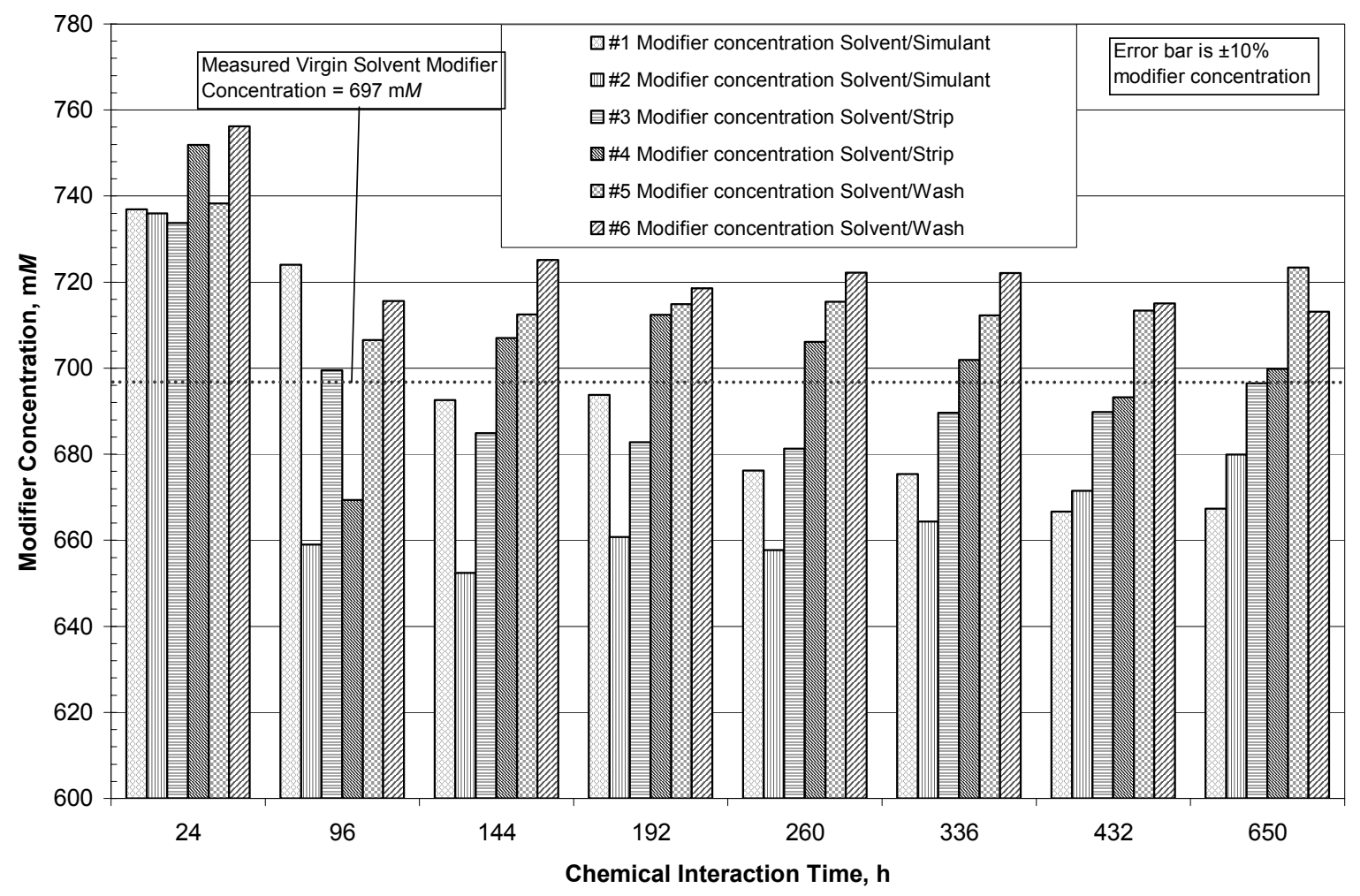

Fig. 17. Modifier concentrations for the chemical interaction tests.

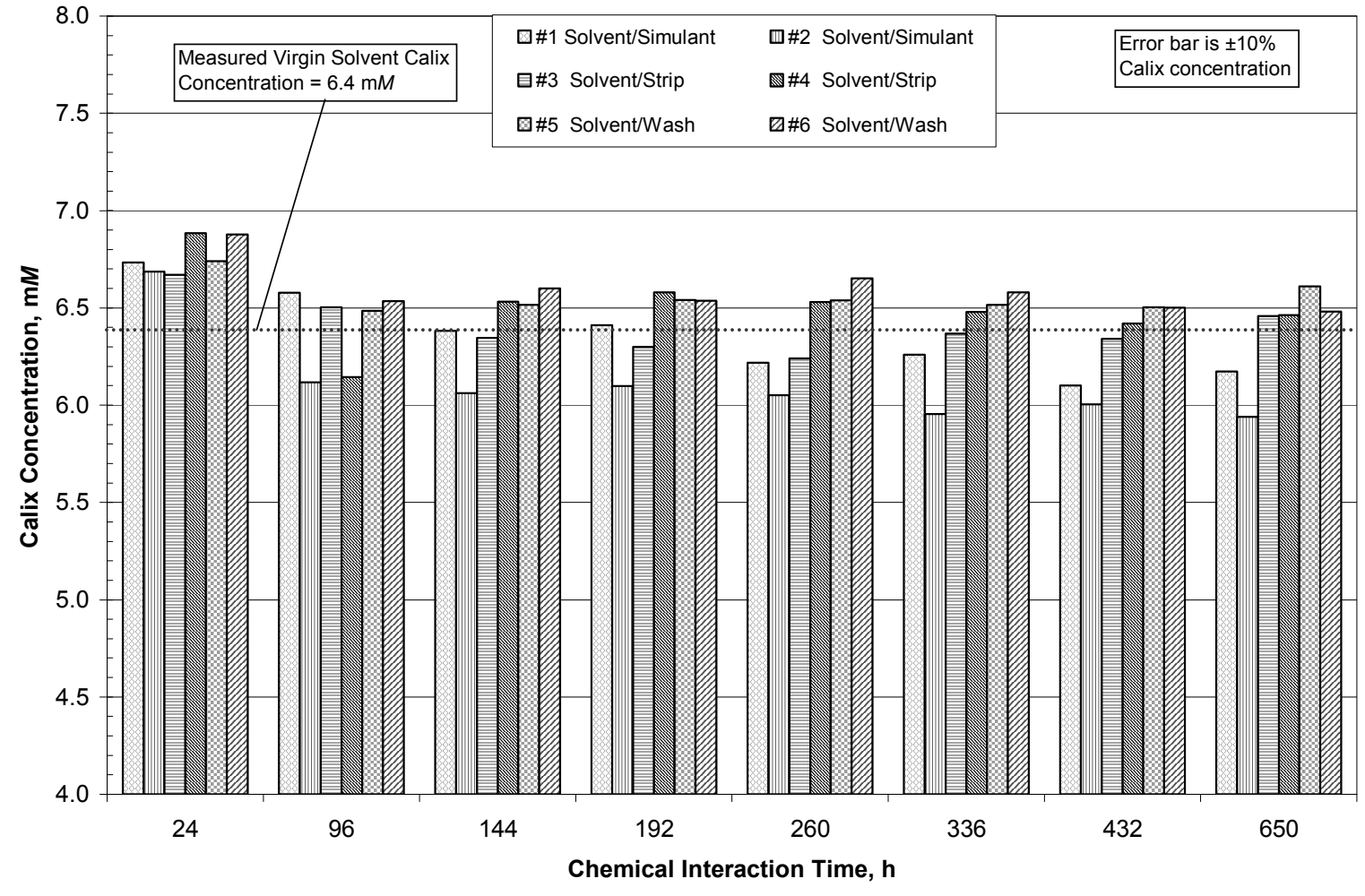

Fig. 18. Calix concentrations for the chemical interaction tests. 


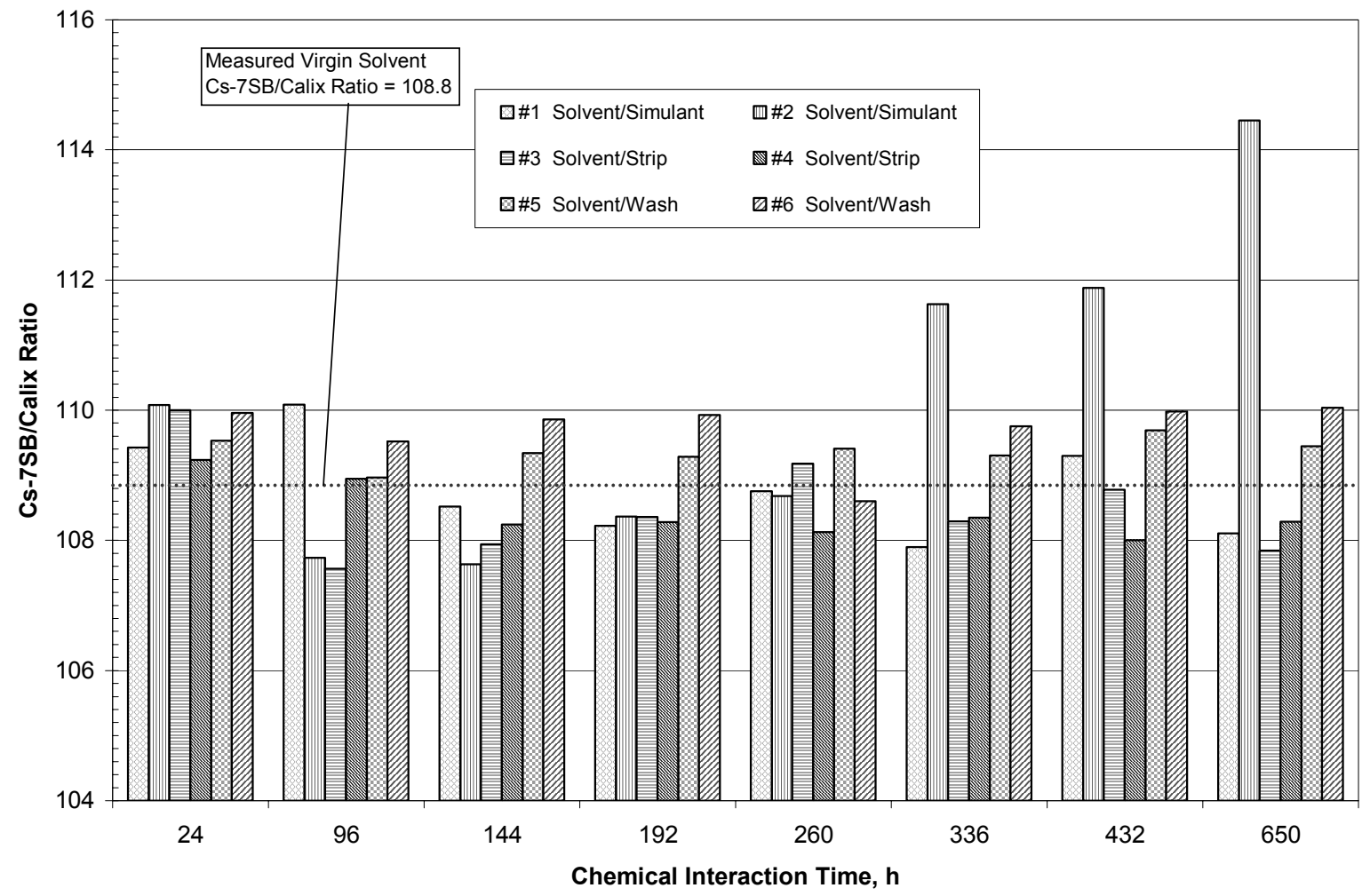

Fig. 19. Ratio of Cs-7SB modifier to calix for the chemical interaction tests.

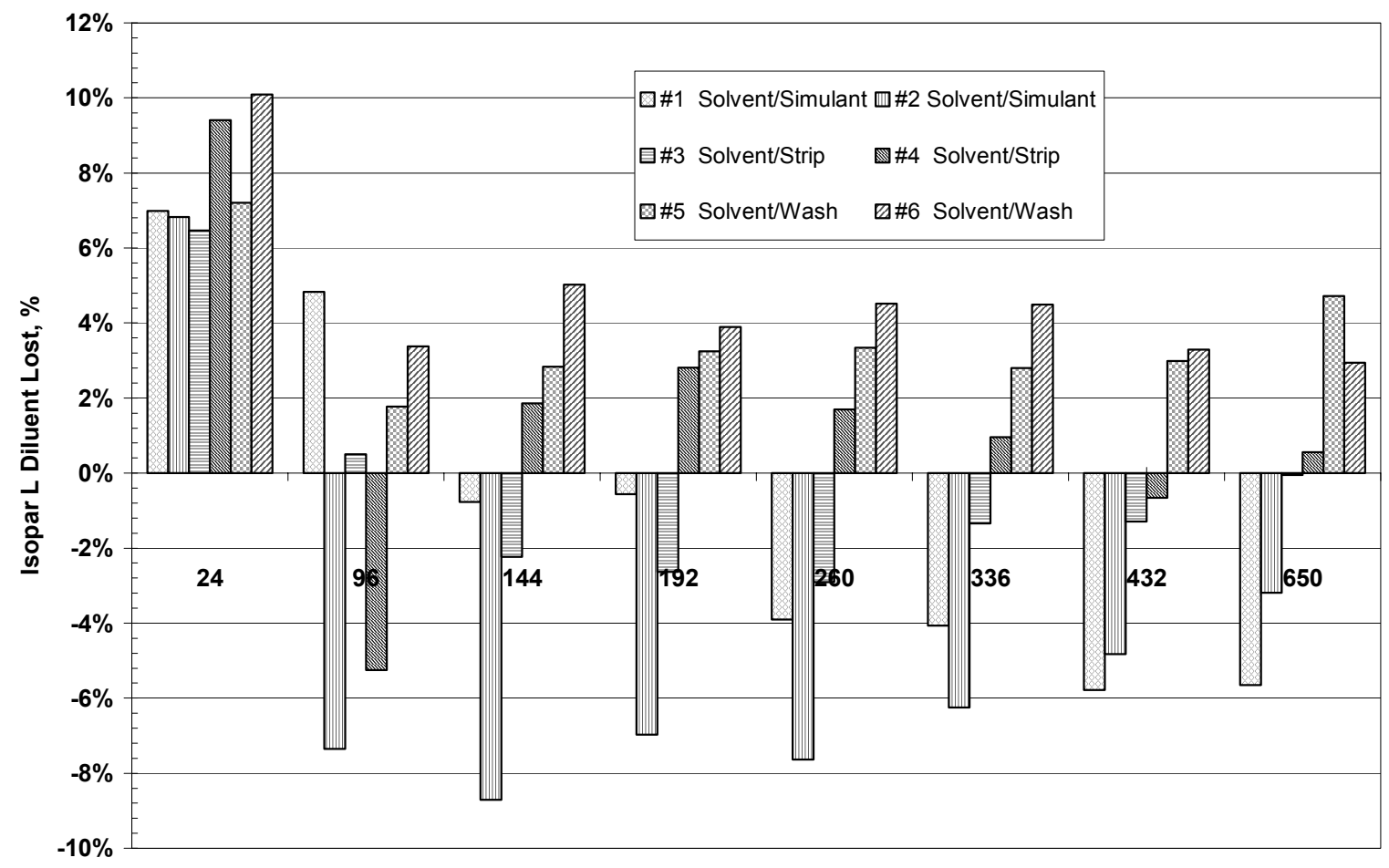

Chemical Interaction Time, h

Fig. 20. Diluent loss in the chemical interaction tests. 


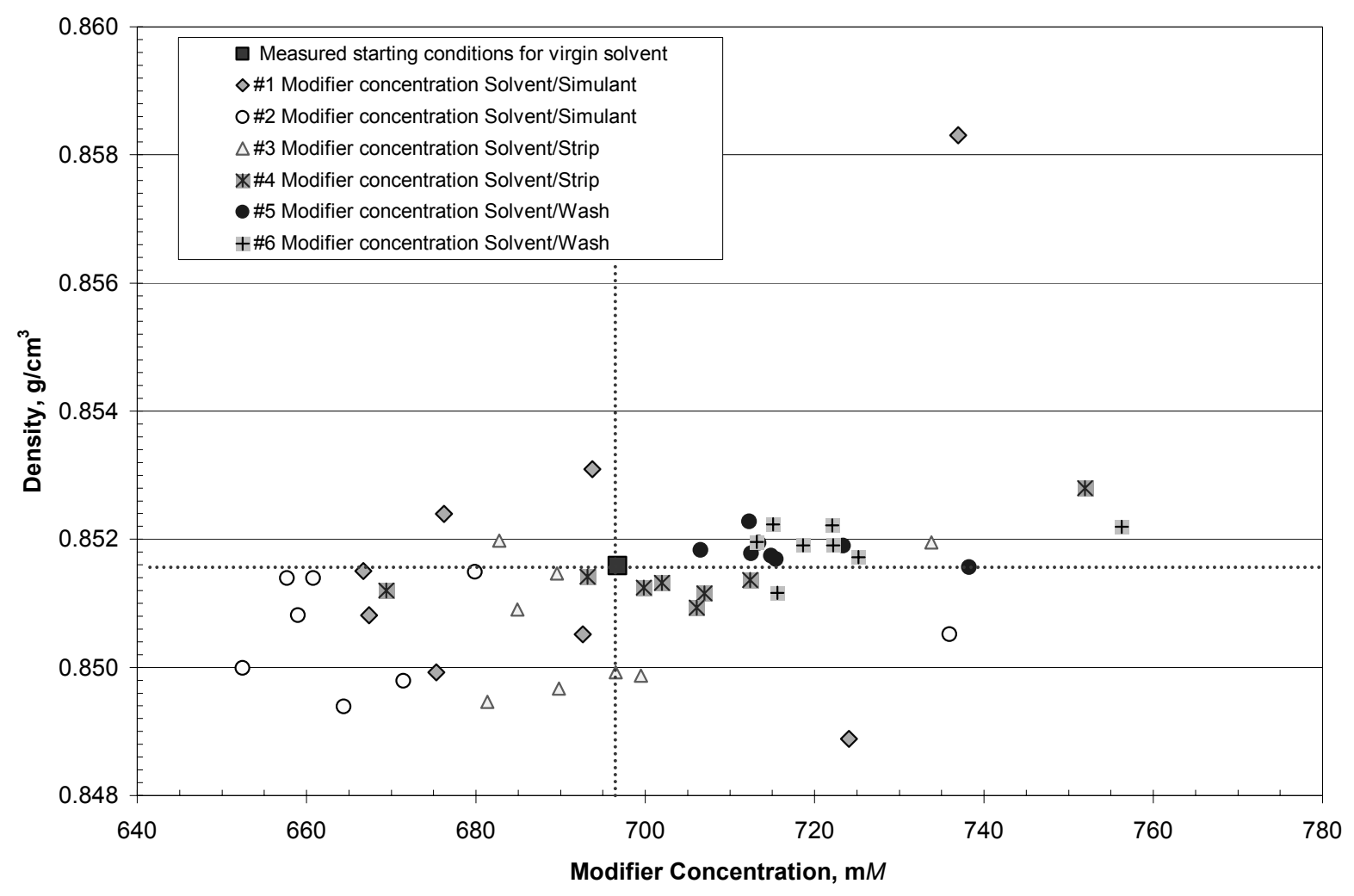

Fig. 21. Density versus modifier concentration for chemical interaction tests.

\section{DISCUSSION AND CONCLUSIONS}

\subsection{CHANGES IN SOLVENT DENSITY}

The primary objective of the testing described in this work was to determine the cause of increases in CSSX solvent density over time. Because changes in solvent density indicate a change in chemical composition and because increased density adversely affects separation of solvent from the denser aqueous solutions present in the CSSX process, identification and control of factors affecting solvent density are essential. A secondary objective of the experimental task was to develop a correlation between solvent properties (density and viscosity with chemical composition) that will permit real-time determination and adjustment of the solvent composition. The results indicate that the diluent does evaporate from the solvent. The following observations may be made regarding the process of solvent evaporation:

- The process is dependent on the airflow as a function of time and temperature of the solvent.

- Evaporation relates to possible diluent loss in the centrifugal contactors.

- The process does not affect modifier-to-TOA or modifier-to-calix ratios because they are not volatile enough to have significant losses from evaporation.

- Evaporation can change the composition of the diluent. Isopar ${ }^{\circledR} \mathrm{L}$ is a mixture of liquid hydrocarbons (C-11-C-15) with a boiling point range of $204-211^{\circ} \mathrm{C}$. Because the compounds in the mixture have differing boiling points, they will also have slightly 
different vapor pressures, affording the possibility of enriching the low-boiling fraction during operations when diluent is added to replace the amount evaporated.

- Evaporation can be determined by measurement of the solvent density. Viscosity can also provide an estimate of the degree of solvent loss, but this measurement is less precise.

The results also indicate that chemical contact alone (chemical interaction) does not appear to lead to loss of diluent (within experimental uncertainty) or changes in solvent composition.

When the test bottles were weighed after $24 \mathrm{~h}$ of evaporation, it was readily apparent that solvent was disappearing from all of them. During the first day, more than $1 \mathrm{~g}$ was lost from each bottle at $25^{\circ} \mathrm{C}$, more than $2.5 \mathrm{~g}$ at $35^{\circ} \mathrm{C}$, and $3-3.5 \mathrm{~g}$ at $45^{\circ} \mathrm{C}$. Density and viscosity measurements both showed increases. Density increased by about $0.3-0.4 \%$ and viscosity increased by about $1-4 \%$. Based on the loss of $1.6 \mathrm{~g}$ from bottle 1 at $25^{\circ} \mathrm{C}$ during the first $24 \mathrm{~h}$, and assuming that the diluent is the only part of the solvent that is evaporating, then about $4 \%$ of the diluent had disappeared. Both NMR and HPLC data confirm the supposition that only the diluent is being lost from the solvent.

\subsection{EFFECTS OF CHANGES IN SOLVENT DENSITY ON SOLVENT COMPOSITION}

Using the original baseline solvent in centrifugal contactor operations, researchers at ANL observed increases in extractant and modifier concentrations, which indicated a loss of diluent, and an increase in the solvent density. They developed a simple density model to predict the increase in extractant and modifier concentrations from the increase in solvent density. The model assumes that no interaction occurs between solvent components that would affect their density. In this model, at $25^{\circ} \mathrm{C}$, calix has a molecular weight of $1149.53 \mathrm{~g} / \mathrm{mol}$ and a density of $1054 \mathrm{~g} / \mathrm{L}$; Cs-7SB has a molecular weight of $338.35 \mathrm{~g} / \mathrm{mol}$ and a density of $1173.5 \mathrm{~g} / \mathrm{L}$; TOA has a molecular weight of $353.69 \mathrm{~g} / \mathrm{mol}$ and a density of $809 \mathrm{~g} / \mathrm{L}$; and Isopar ${ }^{\circledR} \mathrm{L}$ has a density of $759.7 \mathrm{~g} / \mathrm{L}$. Using this model, the density of fresh baseline CSSX solvent at $25^{\circ} \mathrm{C}$ is calculated to be $823 \pm 2 \mathrm{~g} / \mathrm{L}$ and that of the optimized CSSX solvent was calculated to be $851.5 \pm 2.0 \mathrm{~g} / \mathrm{L}$. (The value of $851.6 \mathrm{~g} / \mathrm{L}$ was determined experimentally.)

Based on this model, calculations of the concentrations of the solvent components at the various measured densities were prepared. These are shown in Tables 9-11 for the evaporations of solvent at 25,35 , and $45^{\circ} \mathrm{C}$. These tables compare the calculated results with the values determined by HPLC measurements for the calix and modifier. The HPLC data generally provide concentrations that are about $5-15 \%$ lower than the calculated values for both the calix and Cs-7SB. Given the uncertainty in the HPLC determinations $( \pm 10 \%)$ and the pipetting difficulties discussed earlier, this is reasonable agreement.

When the values of the Cs-7SB concentration calculated from the measured density, as described above, are plotted on the $y$-axis against the HPLC measured values, the plots give slopes from 0.93 for bottle 3 up to 1.33 for bottle 2 as shown in Table 12. The HPLC values; however rarely exceed the error limits of $\pm 10 \%$ for either calix or Cs-7SB and provide support for using the density as an estimation for the concentrations of the solvent components and the loss of the diluent. Density measurement offers real-time capacity to determine solvent component concentrations and the possibility of corrections for solvent diluent loss in real time with laboratory confirmation by the sample analysis using HPLC. 
Table 9. Comparison of solvent composition calculated from measured density and HPLC measurements for evaporation at $25^{\circ} \mathrm{C}$ starting from $1 \mathrm{~L}$ of solvent

\begin{tabular}{|c|c|c|c|c|c|c|c|c|}
\hline \multirow{2}{*}{$\begin{array}{l}\text { Density } \\
\left(\mathrm{g} / \mathrm{cm}^{3}\right)\end{array}$} & \multirow{2}{*}{$\begin{array}{l}{ }^{a} \text { Calc'd } \\
\text { diluent } \\
\text { from } \\
\text { density } \\
(\mathrm{g}) \\
\end{array}$} & \multirow{2}{*}{$\begin{array}{l}{ }^{b} \text { Calc'd } \\
\text { diluent } \\
\text { from } \\
\text { HPLC } \\
(\mathrm{g})\end{array}$} & \multirow[t]{2}{*}{$\begin{array}{c}{ }^{a} \text { Calc'd } \\
\text { Cs-7SB } \\
\text { from } \\
\text { density } \\
(\mathrm{m} M)\end{array}$} & \multirow[t]{2}{*}{$\begin{array}{l}{ }^{a} \text { Calc'd } \\
\text { Calix } \\
\text { from } \\
\text { density } \\
(\mathrm{m} M)\end{array}$} & \multirow[t]{2}{*}{$\begin{array}{l}\text { Calc'd } \\
\text { Cs-7SB } \\
\text { from } \\
\text { HPLC } \\
(\mathrm{m} M)\end{array}$} & \multirow[t]{2}{*}{$\begin{array}{c}\text { Calc'd } \\
\text { Calix } \\
\text { from } \\
\text { HPLC } \\
(\mathrm{m} M) \\
\end{array}$} & \multicolumn{2}{|c|}{$\begin{array}{c}\text { Ratio, } \\
\text { Calc'd/measured }\end{array}$} \\
\hline & & & & & & & Cs-7SB & Calix \\
\hline \multicolumn{9}{|c|}{ Bottle 1} \\
\hline 0.8516 & 588.8 & 589 & 750 & 7.0 & 697 & 6.4 & 1.08 & 1.09 \\
\hline 0.8548 & 564.3 & 511 & 775 & 7.2 & 777 & 7.1 & 1.00 & 1.01 \\
\hline 0.8558 & 556.4 & 535 & 783 & 7.3 & 750 & 6.9 & 1.04 & 1.06 \\
\hline 0.8624 & 509.9 & 490 & 837 & 7.8 & 802 & 7.4 & 1.04 & 1.06 \\
\hline 0.8667 & 481.9 & 462 & 873 & 8.1 & 838 & 7.8 & 1.04 & 1.05 \\
\hline 0.8718 & 452.4 & 426 & 914 & 8.5 & 889 & 8.1 & 1.03 & 1.05 \\
\hline 0.8781 & 419.1 & 409 & 966 & 9.0 & 915 & 8.4 & 1.06 & 1.07 \\
\hline 0.8880 & 373.6 & 369 & 1046 & 9.8 & 983 & 9.0 & 1.06 & 1.09 \\
\hline 0.9043 & 312.0 & 317 & 1180 & 11.0 & 1090 & 9.9 & 1.08 & 1.11 \\
\hline 0.9544 & 187.4 & 227 & 1590 & 14.8 & 1339 & 12.7 & 1.19 & 1.17 \\
\hline \multicolumn{9}{|l|}{ Bottle 2} \\
\hline 0.8516 & 588.8 & 589 & 750 & 7.0 & 750 & 6.4 & 1.00 & 1.09 \\
\hline 0.8527 & 581.0 & 567 & 758 & 7.1 & 718 & 6.7 & 1.06 & 1.06 \\
\hline 0.8545 & 566.4 & 562 & 773 & 7.2 & 723 & 6.7 & 1.07 & 1.07 \\
\hline 0.8589 & 533.4 & 530 & 809 & 7.6 & 756 & 7.0 & 1.07 & 1.08 \\
\hline 0.8626 & 508.2 & 474 & 839 & 7.8 & 822 & 7.6 & 1.02 & 1.04 \\
\hline 0.8662 & 485.0 & 468 & 869 & 8.1 & 829 & 7.6 & 1.05 & 1.07 \\
\hline 0.8662 & 485.0 & 470 & 869 & 8.1 & 827 & 7.6 & 1.05 & 1.07 \\
\hline 0.8792 & 413.9 & 434 & 974 & 9.1 & 877 & 8.0 & 1.11 & 1.13 \\
\hline 0.8898 & 366.0 & 393 & 1061 & 9.9 & 941 & 8.6 & 1.13 & 1.15 \\
\hline 0.9190 & 267.2 & 295 & 1300 & 12.1 & 1141 & 10.6 & 1.14 & 1.14 \\
\hline \multicolumn{9}{|l|}{ Bottle 3} \\
\hline 0.8516 & 588.8 & 589 & 750 & 7.0 & 750 & 6.4 & 1.00 & 1.09 \\
\hline 0.8520 & 586.4 & 573 & 752 & 7.0 & 712 & 6.6 & 1.06 & 1.06 \\
\hline 0.8543 & 568.1 & 602 & 771 & 7.2 & 685 & 6.4 & 1.13 & 1.13 \\
\hline 0.8590 & 533.3 & 541 & 809 & 7.6 & 744 & 6.9 & 1.09 & 1.09 \\
\hline 0.8618 & 513.4 & 503 & 833 & 7.8 & 786 & 7.0 & 1.06 & 1.11 \\
\hline 0.8659 & 487.1 & 450 & 866 & 8.1 & 854 & 7.6 & 1.01 & 1.06 \\
\hline 0.8718 & 452.6 & 457 & 914 & 8.5 & 844 & 7.5 & 1.08 & 1.14 \\
\hline 0.8777 & 421.1 & 371 & 962 & 9.0 & 979 & 8.6 & 0.98 & 1.04 \\
\hline 0.8876 & 375.2 & 316 & 1043 & 9.7 & 1091 & 9.6 & 0.96 & 1.01 \\
\hline 0.9134 & 283.4 & 289 & 1254 & 11.7 & 1156 & 10.8 & 1.08 & 1.09 \\
\hline
\end{tabular}

${ }^{a}$ The measured density was used to calculate the Isopar ${ }^{\mathbb{B}} \mathrm{L}, \mathrm{Cs}-7 \mathrm{SB}$, and calix concentrations starting with $1 \mathrm{~L}$ of solvent using the simple solvent density model (ref. 1).

${ }^{b}$ The measured Cs-7SB was used to calculate the Isopar ${ }^{\circledR} \mathrm{L}$ concentration starting with $1 \mathrm{~L}$ of solvent. 
Table 10. Comparison of solvent composition calculated from measured density and HPLC measurements for evaporation at $35^{\circ} \mathrm{C}$ starting from $1 \mathrm{~L}$ of solvent

\begin{tabular}{|c|c|c|c|c|c|c|c|c|}
\hline \multirow{2}{*}{$\begin{array}{l}\text { Density } \\
\left(\mathrm{g} / \mathrm{cm}^{3}\right)\end{array}$} & \multirow{2}{*}{$\begin{array}{l}{ }^{a} \text { Calc'd } \\
\text { diluent } \\
\text { from } \\
\text { density } \\
(\mathrm{g}) \\
\end{array}$} & \multirow{2}{*}{$\begin{array}{l}{ }^{b} \text { Calc'd } \\
\text { diluent } \\
\text { from } \\
\text { HPLC } \\
(\mathrm{g}) \\
\end{array}$} & \multirow{2}{*}{$\begin{array}{l}{ }^{a} \text { Calc'd } \\
\text { Cs-7SB } \\
\text { from } \\
\text { density } \\
(\mathrm{m} M) \\
\end{array}$} & \multirow{2}{*}{$\begin{array}{l}{ }^{a} \text { Calc'd } \\
\text { Calix } \\
\text { from } \\
\text { density } \\
(\mathrm{m} M) \\
\end{array}$} & \multirow{2}{*}{$\begin{array}{c}\text { Calc'd } \\
\text { Cs-7SB } \\
\text { from } \\
\text { HPLC } \\
(\mathrm{m} M) \\
\end{array}$} & \multirow{2}{*}{$\begin{array}{l}\text { Calc'd } \\
\text { Calix } \\
\text { from } \\
\text { HPLC } \\
(\mathrm{m} M) \\
\end{array}$} & \multicolumn{2}{|c|}{$\begin{array}{c}\text { Ratio, } \\
\text { Calc'd/measured }\end{array}$} \\
\hline & & & & & & & Cs-7SB & Calix \\
\hline \multicolumn{9}{|c|}{ Bottle 4} \\
\hline 0.8516 & 588.8 & 589 & 750 & 7.0 & 697 & 6.4 & 1.08 & 1.09 \\
\hline 0.8559 & 555.4 & 515 & 785 & 7.3 & 773 & 7.1 & 1.02 & 1.03 \\
\hline 0.8587 & 535.1 & 506 & 807 & 7.5 & 782 & 7.2 & 1.03 & 1.04 \\
\hline 0.8727 & 447.2 & 429 & 922 & 8.6 & 883 & 8.1 & 1.04 & 1.06 \\
\hline 0.8832 & 394.8 & 399 & 1007 & 9.4 & 931 & 8.5 & 1.08 & 1.11 \\
\hline 0.8948 & 345.9 & 349 & 1102 & 10.3 & 1020 & 9.2 & 1.08 & 1.11 \\
\hline 0.9116 & 288.8 & 297 & 1239 & 11.6 & 1136 & 10.3 & 1.09 & 1.13 \\
\hline \multicolumn{9}{|c|}{ Bottle 5} \\
\hline 0.8516 & 588.8 & 589 & 750 & 7.0 & 697 & 6.4 & 1.08 & 1.09 \\
\hline 0.8552 & 561.0 & 504 & 779 & 7.3 & 785 & 7.0 & 0.99 & 1.03 \\
\hline 0.8586 & 536.1 & 504 & 806 & 7.5 & 765 & 6.9 & 1.05 & 1.09 \\
\hline 0.8710 & 456.9 & 442 & 908 & 8.5 & 865 & 7.7 & 1.05 & 1.11 \\
\hline 0.8803 & 408.4 & 346 & 984 & 9.2 & 1027 & 9.0 & 0.96 & 1.02 \\
\hline 0.8902 & 364.5 & 345 & 1064 & 9.9 & 1029 & 9.0 & 1.03 & 1.10 \\
\hline 0.9078 & 300.4 & 286 & 1209 & 11.3 & 1163 & 10.2 & 1.04 & 1.11 \\
\hline \multicolumn{9}{|c|}{ Bottle 6} \\
\hline 0.8516 & 588.8 & 589 & 750 & 7.0 & 697 & 6.4 & 1.08 & 1.09 \\
\hline 0.8599 & 526.4 & 520 & 817 & 7.6 & 766 & 6.8 & 1.07 & 1.12 \\
\hline 0.8549 & 563.1 & 495 & 776 & 7.2 & 796 & 7.0 & 0.98 & 1.03 \\
\hline 0.8743 & 438.5 & 424 & 935 & 8.7 & 891 & 7.9 & 1.05 & 1.10 \\
\hline 0.8859 & 382.7 & 368 & 1029 & 9.6 & 986 & 8.8 & 1.04 & 1.10 \\
\hline 0.8984 & 332.4 & 278 & 1132 & 10.6 & 1183 & 10.5 & 0.96 & 1.01 \\
\hline 0.9158 & 276.2 & 266 & 1274 & 11.9 & 1216 & 10.7 & 1.05 & 1.11 \\
\hline
\end{tabular}

${ }^{a}$ The measured density was used to calculate the Isopar ${ }^{\circledR} \mathrm{L}, \mathrm{Cs}-7 \mathrm{SB}$, and calix concentrations starting with $1 \mathrm{~L}$ of solvent using the simple solvent density model (ref. 1).

${ }^{b}$ The measured Cs-7SB was used to calculate the ssopar $^{\circledR} \mathrm{L}$ concentration starting with $1 \mathrm{~L}$ of solvent.. 
Table 11. Comparison of solvent composition calculated from measured density and HPLC measurements for evaporation at $45^{\circ} \mathrm{C}$ starting from $1 \mathrm{~L}$ of solvent

\begin{tabular}{|c|c|c|c|c|c|c|c|c|}
\hline \multirow{2}{*}{$\begin{array}{l}\text { Density } \\
\left(\mathrm{g} / \mathrm{cm}^{3}\right)\end{array}$} & \multirow{2}{*}{$\begin{array}{l}{ }^{a} \text { Calc'd } \\
\text { diluent } \\
\text { from } \\
\text { density } \\
\text { (g) }\end{array}$} & \multirow{2}{*}{$\begin{array}{l}{ }^{b} \text { Calc'd } \\
\text { diluent } \\
\text { from } \\
\text { HPLC } \\
(\mathrm{g}) \\
\end{array}$} & \multirow{2}{*}{$\begin{array}{c}{ }^{a} \text { Calc'd } \\
\text { Cs-7SB } \\
\text { from } \\
\text { density } \\
(\mathrm{m} M)\end{array}$} & \multirow{2}{*}{$\begin{array}{l}{ }^{a} \text { Calc'd } \\
\text { Calix } \\
\text { from } \\
\text { density } \\
(\mathrm{m} M) \\
\end{array}$} & \multirow{2}{*}{$\begin{array}{c}\text { Calc'd } \\
\text { Cs-7SB } \\
\text { from } \\
\text { HPLC } \\
(\mathrm{m} M) \\
\end{array}$} & \multirow{2}{*}{$\begin{array}{l}\text { Calc'd } \\
\text { Calix } \\
\text { from } \\
\text { HPLC } \\
(\mathrm{m} M)\end{array}$} & \multicolumn{2}{|c|}{$\begin{array}{c}\text { Ratio, } \\
\text { Calc'd/measured }\end{array}$} \\
\hline & & & & & & & Cs-7SB & Calix \\
\hline \multicolumn{9}{|c|}{ Bottle 7} \\
\hline 0.8516 & 588.8 & 589 & 750 & 7.0 & 697 & 6.4 & 1.08 & 1.09 \\
\hline 0.8553 & 560.6 & 540 & 779 & 7.3 & 745 & 6.8 & 1.05 & 1.07 \\
\hline 0.8607 & 521.1 & 504 & 823 & 7.7 & 784 & 7.2 & 1.05 & 1.07 \\
\hline 0.8767 & 426.1 & 406 & 954 & 8.9 & 920 & 8.4 & 1.04 & 1.07 \\
\hline 0.8897 & 366.5 & 376 & 1060 & 9.9 & 970 & 8.7 & 1.09 & 1.14 \\
\hline 0.9049 & 309.8 & 311 & 1185 & 11.1 & 1102 & 9.8 & 1.08 & 1.12 \\
\hline 0.9207 & 262.6 & 270 & 1314 & 12.3 & 1207 & 10.8 & 1.09 & 1.14 \\
\hline \multicolumn{9}{|l|}{ Bottle 8} \\
\hline 0.8516 & 588.8 & 589 & 750 & 7.0 & 697 & 6.4 & 1.08 & 1.09 \\
\hline 0.8558 & 556.9 & 499 & 783 & 7.3 & 791 & 7.2 & 0.99 & 1.02 \\
\hline 0.8615 & 516.0 & 477 & 830 & 7.7 & 818 & 7.4 & 1.01 & 1.05 \\
\hline 0.8802 & 408.7 & 380 & 983 & 9.2 & 962 & 8.6 & 1.02 & 1.06 \\
\hline 0.8958 & 342.0 & 324 & 1111 & 10.4 & 1074 & 9.6 & 1.03 & 1.08 \\
\hline 0.9164 & 274.7 & 263 & 1278 & 11.9 & 1225 & 10.9 & 1.04 & 1.10 \\
\hline 0.9348 & 227.5 & 231 & 1430 & 13.3 & 1326 & 11.8 & 1.08 & 1.13 \\
\hline \multicolumn{9}{|l|}{ Bottle 9} \\
\hline 0.8516 & 588.8 & 589 & 750 & 7.0 & 697 & 6.4 & 1.08 & 1.09 \\
\hline 0.8561 & 554.1 & 508 & 786 & 7.3 & 780 & 7.0 & 1.01 & 1.04 \\
\hline 0.8619 & 512.8 & 489 & 833 & 7.8 & 803 & 7.2 & 1.04 & 1.08 \\
\hline 0.8818 & 401.4 & 390 & 996 & 9.3 & 946 & 8.4 & 1.05 & 1.10 \\
\hline 0.8970 & 337.5 & 337 & 1121 & 10.5 & 1046 & 9.3 & 1.07 & 1.12 \\
\hline 0.9167 & 273.7 & 276 & 1281 & 12.0 & 1189 & 10.6 & 1.08 & 1.12 \\
\hline 0.9322 & 233.6 & 236 & 1408 & 13.1 & 1307 & 11.6 & 1.08 & 1.13 \\
\hline
\end{tabular}

${ }^{a}$ The measured density was used to calculate the Isopar ${ }^{\mathbb{B}} \mathrm{L}, \mathrm{Cs}-7 \mathrm{SB}$, and calix concentrations starting with $1 \mathrm{~L}$ of solvent using the simple solvent density model (ref. 1).

${ }^{b}$ The measured Cs-7SB was used to calculate the Isopar ${ }^{\circledR} \mathrm{L}$ concentration starting with $1 \mathrm{~L}$ of solvent. 


\section{Table 12 Correlation of calculated and measured values of Cs-7SB for density changes}

\begin{tabular}{ccccc}
\hline $\begin{array}{c}\text { Sample } \\
\text { bottle no. }\end{array}$ & $\begin{array}{c}\text { Temperature } \\
\left({ }^{\circ} \mathrm{C}\right)\end{array}$ & Slope & Intercept & Correlation, $\mathrm{R}^{2}$ \\
\hline 1 & 25 & 1.141 & -78.7 & 0.978 \\
2 & 25 & 1.329 & -213.8 & 0.981 \\
3 & 25 & 0.928 & +97.5 & 0.956 \\
4 & 35 & 0.942 & +80.1 & 0.916 \\
5 & 35 & 1.177 & -101.8 & 0.989 \\
6 & 35 & 0.962 & +58.6 & 0.957 \\
7 & 45 & 1.108 & -66.8 & 0.990 \\
8 & 45 & 1.129 & -66.4 & 0.995 \\
9 & 45 & 1.130 & -56.4 & 0.994 \\
\hline
\end{tabular}

Researchers at ANL also checked the rate of diluent loss from the solvent to determine if it was consistent with the estimated diluent vapor pressure. ${ }^{3}$ The rate of diluent loss was calculated by using the change in solvent density and the loss in solvent volume during testing. From data supplied by the manufacturer, the vapor pressure for Isopar ${ }^{\circledR} \mathrm{L}$ was estimated to be $31 \mathrm{~Pa}$ at $20^{\circ} \mathrm{C}$ and $124 \mathrm{~Pa}$ at $40^{\circ} \mathrm{C}$, neglecting the effect of the other solvent components. The diluent losses observed at ANL could be explained by using these vapor pressures along with an estimate of the total gas flow through the 2 -cm contactor. The estimated vapor pressures for the temperatures used in these tests are 44,88 , and $175 \mathrm{~Pa}$ at 25,35 , and $45^{\circ} \mathrm{C}$, respectively. If the volume of vaporized Isopar ${ }^{\circledR} \mathrm{L}$ lost by evaporation during each period is divided by the volume of air passed over the solvent during the period, an estimate of the vapor pressure of the Isopar ${ }^{\mathbb{B}} \mathrm{L}$ for each bottle results. The vapor pressure calculations for the nine bottles are shown in Table 13. At $25^{\circ} \mathrm{C}$, the estimated vapor pressure was $44 \mathrm{~Pa}$ and that calculated from the air rate and mass of diluent lost was about 39-40 Pa for the three bottles. This is fairly good agreement, given the possible variations in airflow rates over the 4-week test. The values for $35^{\circ} \mathrm{C}$ should have been about $88 \mathrm{~Pa}$, but the calculated vapor pressure was higher for two of the bottles and lower for the third. The values for $45^{\circ} \mathrm{C}$ were just slightly higher than these for $35^{\circ} \mathrm{C}$. However, this was expected because the air going to the bottles was not heated but was at (or just slightly higher) than ambient temperature. These results again point out the need to reduce the airflow through the contactors to the minimum possible level, and to keep the air that does pass through at the minimum practical temperature.

\subsection{EFFECTS OF SOLVENT DENSITY AND VISCOSITY ON CENTRIFUGAL CONTACTOR OPERATION}

A cursory analysis of the effect of density and viscosity changes on contactor throughput has been performed, using a contactor hydraulic model developed at ORNL based on force balances derived by ANL researchers. Viscosity and density values were taken from data obtained from bottle 1 , which was purged with dry gas at $25^{\circ} \mathrm{C}$. Calculations were performed at CSSX stripping conditions where the solvent is contacted with $0.001 M \mathrm{HNO}_{3}$ strip solution at an organic-to-aqueous phase ratio of 5.0. Contactor dimensions input to the model are those of a 5-cm CINC, Inc., model V-2 unit. Solution properties and predicted maximum throughputs are listed in Table 14. 
Table 13. Vapor pressure calculations for evaporation of $\operatorname{Isopar}^{\circledR} \mathbf{L}$

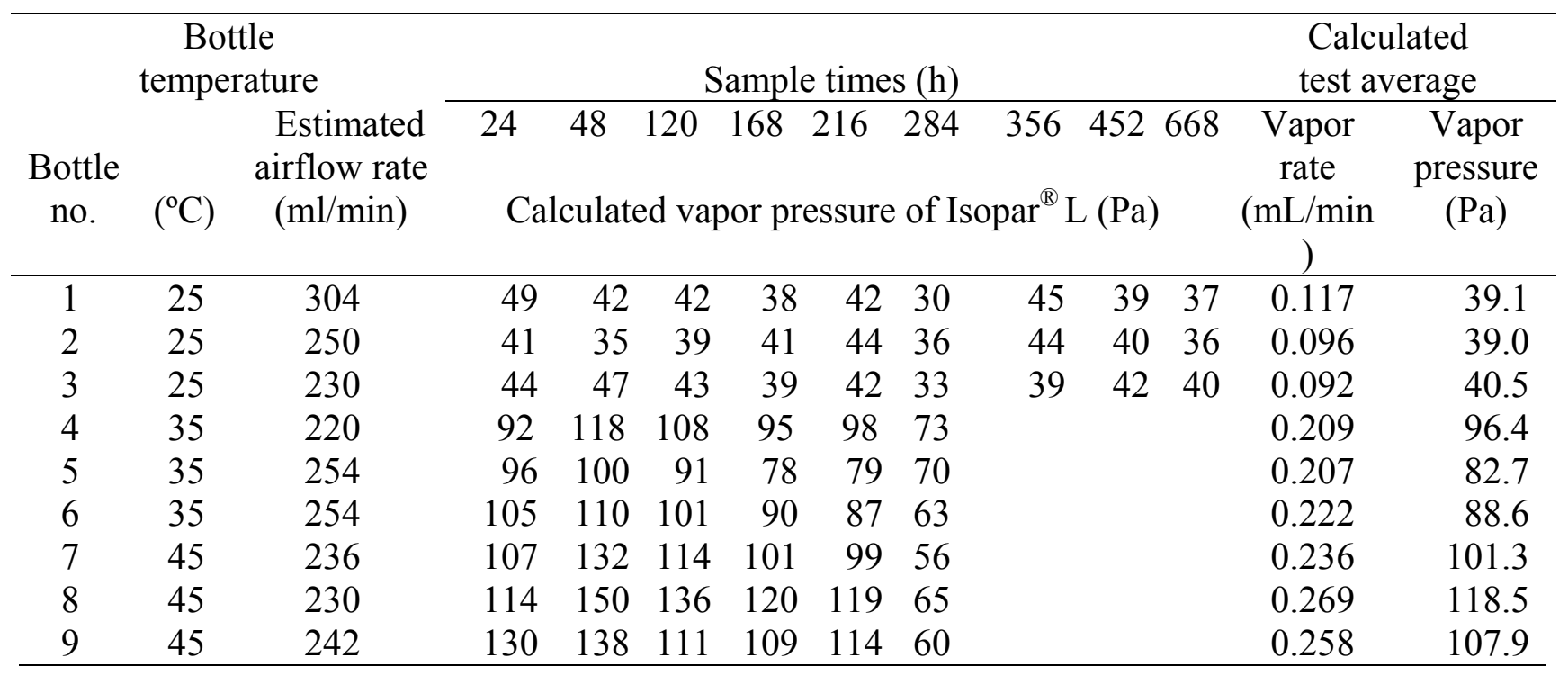

Table 14. Solvent properties and predicted contactor throughputs

\begin{tabular}{cccc}
\hline $\begin{array}{c}\text { Solvent density } \\
\left(\mathrm{g} / \mathrm{cm}^{3}\right)\end{array}$ & $\begin{array}{c}\text { Solvent viscosity } \\
(\mathrm{cP})\end{array}$ & $\begin{array}{c}\text { Radius of heavy-phase } \\
\text { weir }(\mathrm{mm})\end{array}$ & $\begin{array}{c}\text { Maximum throughput } \\
\text { at 3500 rpm }(\mathrm{L} / \mathrm{min})^{a}\end{array}$ \\
\hline 0.852 & 3.50 & 11.923 & 3.391 \\
0.862 & 3.80 & 11.923 & 3.615 \\
0.888 & 5.20 & 11.923 & 2.435 \\
0.954 & 11.80 & 11.923 & 0.0 \\
0.954 & 11.80 & 10.795 & 2.452 \\
\hline
\end{tabular}

${ }^{a}$ Throughput results are based on a fixed dispersion number value of $1.10 \times 10^{-3}$. The aqueous solution viscosity and density were fixed at $1.0 \mathrm{cP}$ and $1.00 \mathrm{~g} / \mathrm{mL}$, respectively.

It is important to note that the dispersion number used is that for virgin solvent (i.e., solvent that has not undergone evaporation) and that this value was not changed in the various cases considered. This unrealistic approach results in extremely optimistic flow rates for systems in which the solvent density and viscosity differ from the baseline values. Dispersion numbers for solvent that has undergone evaporation are not available at present.

Discounting a "noise level" increase in throughput between the first two condition sets, the results indicate that the throughput is significantly affected by changes in solvent properties that occur as a result of evaporation. Loss of throughput is due to an outward shift in the position of the organic/aqueous interface within the contactor rotor as the organic-phase density increases. Under the fourth condition set, the phase boundary shifts outward to such an extent that the organic (or light) phase is directed across the heavy-phase weir along with the aqueous contactor effluent, regardless of how low the flow rate is. This results in the loss of throughput. In order for the contactor to "pump", it must support a large enough volume of liquid that the light phase liquid layer at the top of the rotor reaches inward to the organic (light phase) weir. When the difference in phase densities is great enough, this volume is obtained only when a 
substantial aqueous (heavy phase) layer is present along the inner wall of the rotor. As the lightphase density increases, the mass that is supported by the angular acceleration of the rotor is reached with a decreased volume of heavy phase solution and an increased volume of light solution. Consequently, the phase boundary shifts outward to a position under the aqueous underflow, and the inner surface of the light phase shifts outward away from the light phase weir. The observable result is flow of both phases from the heavy phase outlet. There is throughput, but it is useless since there is no separation. As shown in Table 14, the interface shift can be compensated for by reducing the diameter of the heavy-phase weir. Such a modification can be accomplished easily when hands-on equipment maintenance is possible but is extremely difficult under remote operation and maintenance restrictions.

Computer simulations were run based on 0 to $40 \%$ diluent loss under stripping and extraction conditions. The results show little predicted change with changes in density and viscosity. Without the dispersion numbers for the composition altered solvents, the model cannot predict the accurate loss of performance as a function of diluent loss. The model results do show a failure point, but that can be attributed to a shift in the interface described above.

In further consideration of the changing solvent composition during evaporations, a simple correlation for the cesium distribution coefficient, $\mathrm{D}_{\mathrm{Cs}}\left[\log \left(\mathrm{D}_{\mathrm{Cs}}\right)\right.$ vs $\log ($ calix $)$ and $\log \left(\mathrm{D}_{\mathrm{Cs}}\right)$ vs $\log (\mathrm{Cs}-7 \mathrm{SB})$ produce linear slopes], was used to obtain $\mathrm{D}$ values based on the extrapolation of experimental results obtained while testing different solvent compositions of calix or modifier prior to optimization..$^{5}$ At modifier values greater than $1 M$, any calix values greater than $10 \mathrm{~m} M$ are outside the range tested last year. The calculated D values for extraction, two scrub stages, and four strip stages, shown in Table 15, are reasonable based on experience. ${ }^{113}$ When the stripping $\mathrm{D}$ values increase to 0.2 , the cesium will not be removed from the solvent as efficiently as is desired. The number of stripping stages can be increased, but extraction factors greater than 1.0 at the strip O:A of 5 could easily be reached when $\mathrm{D}_{\mathrm{Cs}}$ is greater than or equal to 0.2. This can occur in the first strip stage (as shown in the Table 15), at modifier and calix concentrations of $\sim 1050$ and $\sim 10 \mathrm{mM}$, respectively, and a solvent density of $\sim 0.89 \mathrm{~g} / \mathrm{cm}^{3}$ (representing about $30 \%$ loss of diluent).

Table 15. Calculated D values for the extraction, scrub, and strip stages with increasing concentrations of modifier and calix

\begin{tabular}{ccccccccc}
\hline $\begin{array}{c}\text { Cs-7SB } \\
(\mathrm{m} M)\end{array}$ & $\begin{array}{c}\text { Calix } \\
(\mathrm{m} M)\end{array}$ & $\begin{array}{c}\text { Extract } \\
\mathrm{D}_{\mathrm{Cs}}\end{array}$ & $\begin{array}{c}\text { Scrub \#1 } \\
\mathrm{D}_{\mathrm{Cs}}\end{array}$ & $\begin{array}{c}\text { Scrub \#2 } \\
\mathrm{D}_{\mathrm{Cs}}\end{array}$ & $\begin{array}{c}\text { Strip \#1 } \\
\mathrm{D}_{\mathrm{Cs}}\end{array}$ & $\begin{array}{c}\text { Strip \#2 } \\
\mathrm{D}_{\mathrm{Cs}}\end{array}$ & $\begin{array}{c}\text { Strip \#3 } \\
\mathrm{D}_{\mathrm{Cs}}\end{array}$ & $\begin{array}{c}\text { Strip \#4 } \\
\mathrm{D}_{\mathrm{Cs}}\end{array}$ \\
\hline 750 & 7.0 & 14.13 & 1.32 & 1.35 & 0.104 & 0.062 & 0.049 & 0.043 \\
773 & 7.2 & 14.74 & 1.39 & 1.42 & 0.110 & 0.065 & 0.052 & 0.045 \\
784 & 7.3 & 15.03 & 1.43 & 1.45 & 0.113 & 0.067 & 0.053 & 0.046 \\
809 & 7.6 & 15.73 & 1.51 & 1.52 & 0.119 & 0.071 & 0.056 & 0.049 \\
837. & 7.8 & 16.52 & 1.60 & 1.60 & 0.127 & 0.076 & 0.059 & 0.052 \\
873 & 8.2 & 17.56 & 1.72 & 1.71 & 0.137 & 0.082 & 0.064 & 0.055 \\
914 & 8.5 & 18.76 & 1.86 & 1.83 & 0.148 & 0.089 & 0.070 & 0.060 \\
966 & 9.0 & 20.32 & 2.03 & 1.99 & 0.163 & 0.099 & 0.077 & 0.065 \\
1007 & 9.4 & 21.62 & 2.17 & 2.12 & 0.176 & 0.107 & 0.083 & 0.069 \\
1046 & 9.8 & 22.89 & 2.31 & 2.24 & 0.188 & 0.115 & 0.089 & 0.073 \\
1102 & 10.3 & 24.73 & 2.50 & 2.42 & 0.206 & 0.127 & 0.098 & 0.078 \\
1180 & 11.0 & 27.38 & 2.76 & 2.68 & 0.232 & 0.144 & 0.110 & 0.085 \\
1300 & 12.1 & 31.75 & 3.18 & 3.09 & 0.275 & 0.174 & 0.132 & 0.095 \\
1430 & 13.3 & 36.72 & 3.62 & 3.55 & 0.323 & 0.209 & 0.157 & 0.105 \\
1590 & 14.8 & 43.36 & 4.16 & 4.15 & 0.388 & 0.258 & 0.192 & 0.116 \\
\hline
\end{tabular}




\section{REFERENCES}

1. R. A. Leonard, S. B. Aase, H. A. Arafat, D. B. Chamberlain, C. Conner, J. R. Falkenberg, M. C. Regalbuto, and G. F. Vandegrift, Multi-Day Test of the Caustic-Side Solvent Extraction Flowsheet for Cesium Removal from a Simulated SRS Tank Waste, ANL-02/11, Argonne National Laboratory, Argonne, Illinois, January 15, 2002.

2.. J. F. Birdwell and K. K. Anderson, Evaluation of 5-cm Centrifugal Contactor Hydraulic and Mass Transfer Performance for Caustic-Side Solvent Extraction of Cesium, ORNL/TM-2001/137, Oak Ridge National Laboratory, Oak Ridge, Tennessee, August 2001.

3. R. A. Leonard, S. B. Aase, H. A. Arafat, C. Conner, J. R. Falkenberg, M. C. Regalbuto, and G. F. Vandegrift, Simulant Flowsheet Test With Modified Solvent For Cesium Removal Using CausticSide Solvent Extraction, ANL-02/22, Argonne National Laboratory, Argonne, Illinois, April 22, 2002.

4. L. N. Klatt, J. F. Birdwell, Jr., P. V. Bonnesen, L. H. Delmau, L. J. Foote, D. D. Lee, R. A. Leonard, R. G. Levitskaia, M. P. Maskarinec, and B. A. Moyer, Caustic-Side Solvent Extraction SolventComposition Recommendation, ORNL/TM-2001/258, Oak Ridge National Laboratory, Oak Ridge, Tennessee January 2002.

5. Standard Test Methods for Specific Gravity, Apparent, of Liquid Industrial Chemicals, ASTM D891-95, American Society for Testing and Materials, 2000.

6. Standard Test Methods for Specific Gravity of Water and Brine, ASTM D1429-95, American Society for Testing and Materials, 1999.

7. Standard Practice for Calibration of Laboratory Volumetric Apparatus, ASTM E542-00, American Society for Testing and Materials, 2000.

8. Standard Test Method for Rheological Properties of Non-Newtonian Materials by Rotational (Brookfield type) Viscometer, ASTM D2196-99, American Society for Testing and Materials, 1999.

9. The Brookfield Digital Viscometer Model DV-II Operating Instructions, Manual No. M/85-160-F, Brookfield Engineering Laboratories, Inc., Stoughton, Massachusetts, 1985.

10. W. V. Steele, Vapor Pressure of 1-(2,2,3,3-Tetrafluoropropoxy)-3-(4-sec-butylphenoxy)-2-propanol ORNL/TM-2001/287, Oak Ridge National Laboratory, Oak Ridge, Tennessee, January 2002.

11. L. H. Delmau, personal communication, e-mail to author, September 9, 2002. 


\section{INTERNAL DISTRIBUTION}

1-2. J. F. Birdwell, Jr.

3. P. V. Bonnesen

4. L. H. Delmau

5. R. D. Hunt

6-9. D. D. Lee

10. C. P. McGinnis

11. B. A. Moyer

12. B. A. Tomkins

13. J. F. Walker

14. ORNL Central Research Library

15. Laboratory Records, RC

16. Laboratory Records, OSTI

\section{EXTERNAL DISTRIBUTION}

17. J. T. Carter, Westinghouse Savannah River Company, P.O. Box 616, Building 704-3B, Aiken, SC 29808

18. D. Chamberlain, Argonne National Laboratory, Building 205, 9700 South Cass Avenue, Argonne, IL 60439

19. N. F. Chapman, Westinghouse Savannah River Company, P.O. Box 616, Building 704-3B, Aiken, SC 29808

20. C. Conner, Argonne National Laboratory, Building 205, 9700 South Cass Avenue, Argonne, IL 60439

21. R. G. Edwards, Westinghouse Savannah River Company, P.O. Box 616, Building 704-3B, Aiken, SC 29808

22. S. D. Fink, Westinghouse Savannah River Company, P.O. Box 616, Building 773-A, Aiken, SC 29808

23. H. D. Harmon, Tank Focus Area Salt Processing Program, P.O. Box 616, Building 704-3N, Aiken, SC 29808

24. R. T. Jones, Westinghouse Savannah River Company, P.O. Box 616, Building 704-3N, Aiken, SC 29808

25. R. A. Leonard, Argonne National Laboratory, Building 205, 9700 South Cass Avenue, Argonne, IL 60439

26. J. W. McCullough, Jr., U.S. Department of Energy, Savannah River Operations Office, Bldg. 704-3N, Aiken, SC 29808

27. J. R. Noble-Dial, U.S. Department of Energy, Oak Ridge Operations Office, P.O. Box 2001, Oak Ridge, TN 37831-8620 
28. Michael Norato, Westinghouse Savannah River Company, P.O. Box 616, Building 773-A, Aiken, SC 29808

29. Robert Pierce, Westinghouse Savannah River Company, P.O. Box 616, Building 773-A, Aiken, SC 29808

30. S. N. Schlahta, Battelle, Pacific Northwest National Lab, P.O. Box 999 / MS K9-14 Richland, WA 99352

31. P. C. Suggs, U.S. Department of Energy, Savannah River Operations Office, P.O. Box A, Building 704-3N, Aiken, SC 29808

32. W. L. Tamosaitis, Westinghouse Savannah River Company, P.O. Box 616, Building 773-A, Aiken, SC 29808

33. M. Thompson, Westinghouse Savannah River Company, P.O. Box 616, Building 773-A, Aiken, SC 29808

34. T. A. Todd, Idaho National Engineering \& Environmental Laboratory, Building 637, MS-5218, Idaho Falls, ID 834415-5218

35. G. Vandegrift, Argonne National Laboratory, Building 205, 9700 South Cass Avenue, Argonne, IL 60439

36. D. D. Walker, Westinghouse Savannah River Company, P.O. Box 616, Building 773-A, Aiken, SC 29808

37. D. Wester, Westinghouse Savannah River Company, P.O. Box 616, Building 773-A, Aiken, SC 29808

38. W. R. Wilmarth, Westinghouse Savannah River Company, P.O. Box 616, Building 773-A, Aiken, SC 29808

39. Tanks Focus Area Technical Team, c/o B. J. Williams, Pacific Northwest National Laboratory, P.O. Box 999, MSIN K9-69, Richland, WA 99352

40. Tanks Focus Area Field Lead, c/o T. P. Pietrok, U.S. Department of Energy, Richland Operations Office, P.O. Box 550, K8-50, Richland, WA 99352

41. Tanks Focus Area Headquarters Program Manager, c/o K. D. Gerdes, DOE Office of Science and Technology, 19901 Germantown Rd., 1154 Cloverleaf Building, Germantown, MD 20874-1290 